\title{
Análise filogenética e implicações sistemáticas e evolutivas nos Cuculiformes (Aves) com base na osteologia, comportamento e ecologia
}

\author{
Sérgio R. Posso ${ }^{1} \&$ Reginaldo J. Donatelli ${ }^{2}$
}

\author{
${ }_{1}$ Autor correspondente. Departamento de Ciências Biológicas, Universidade Federal do Mato Grosso. 78735-901 \\ Rondonópolis, Mato Grosso, Brasil. \\ ${ }^{2}$ Laboratório de Vertebrados, Departamento de Ciências Biológicas, Universidade Estadual Paulista. Caixa Postal 473, \\ 17033-360 Bauru, São Paulo, Brasil.
}

\begin{abstract}
Phylogenetic analysis of Cuculiformes (Aves) based on osteology, behavior and ecology: systematics and evolutionary implications. Despite of many recent cladistic studies the classification of the order Cuculiformes is still controversial. Thus, we performed the most extensive cladistic analysis of the cuckoos, inferred based on 250 characters of the osteology, behavior and ecology. The resulting analysis provided 18 equally parsimonious trees (768 steps, $\mathrm{Cl}=0.4779, \mathrm{RI}=0.8080$ and $\mathrm{CRI}=0.3861)$. According to the topology of the strict consensus cladogram: a) the monophyly of Cuculiformes order is corroborated; b) the order is divided in two groups: a) Coua/Carpococcyx and b) others cuckoos (Neomorphidae, (Crotophagidae, (Taperal Dromoccoccyx, (Cuculidae))), being the systematic position of Centropus ambiguous between these two groups; c) the terrestrial cuckoos are considered basal and a paraphyletic group and the arboreal cuckoos are derived and monophyletic; d) brood parasitism evolved twice in the cuckoos (in Tapera/ Dromoccoccyx and in Cuculidae).
\end{abstract}

KEY WORDS. Birds; classification; cuckoos; evolution.

RESUMO. Têm-se notado vários estudos recentes em filogenia com os Cuculiformes, no entanto nestes trabalhos ainda há divergências. Apresenta-se aqui uma nova e ampla análise filogenética para os Cuculiformes com base em 250 caracteres da osteologia, comportamento e ecologia. Esta análise resultou em 18 cladogramas igualmente parcimoniosos (768 passos, IC $=0.4779, \mathrm{IR}=0.8080$ e ICR $=0.3861)$. De acordo com o cladograma de consenso estrito se pode observar: a) o monofiletismo dos Cuculiformes; b) a ordem dividida em dois grupos: a) Coual Carpococcyx e; b) demais cucos (Neomorphidae, (Crotophagidae, (Tapera / Dromoccoccyx, (Cuculidae))), no entanto a posição sistemática de Centropus é ambígua entre estes dois grandes grupos; c) os cucos terrestres basais e parafiléticos e os cucos arbóreos derivados e monofiléticos. Ainda, propõe-se que o comportamento de parasitar ninho tenha surgido duas vezes independentemente (uma em Taperal Dromoccoccyx e outra dentro de Cuculidae). PALAVRAS-CHAVE. Classificação; cucos; evolução.

Os Cuculiformes, denominados de cucos, são cosmopolitas ocupando todos os biomas tropicais com exceção de algumas ilhas oceânicas (Hughes 1996). Todavia, a maioria está concentrada no Hemisfério Sul. Somente Coccyzus Vieillot, 1816, Cuculus Linnaeus, 1758, Geococcyx Wagler, 1831 e Clamator Kaup, 1829, sendo os dois primeiros migratórios, possuem representantes nas regiões Paleártica e Neártica (PAYNe 1997).

Esta família apresenta significativa variação em relação aos aspectos ecológicos, comportamentais, anatômicos e à plumagem (Shufeldt 1901, PAYNe 1997) que, provavelmente, é resultado de uma longa história evolutiva (Feduccia 1996) e ampla distribuição geográfica (PAYNE 1997). Os cucos são conhecidos principalmente por hábitos gregários em algumas espécies e com- portamentos peculiares em relação à reprodução (PAYNE 1997), sendo provavelmente a família que apresenta maior diversidade de comportamentos reprodutivos dentro da classe Aves (KRÜGER \& DAVIEs 2002). Embora a maioria das espécies adote a estratégia de cuidar dos filhotes, 53 espécies parasitam ninhos (KRÜGER \& DAVIES 2002) e este é o aspecto mais estudado nos cucos, onde se podem encontrar relatos detalhados de coevolução com aves parasitadas (Payne 1974, Davies \& Brooke 1988, 1989a,b, Soler et al. 1994, Payne 1997, Davies 2000, Krüger \& Davies 2002).

Há cucos predominantemente terrícolas, alguns que apresentam ambos os comportamentos terrícola e arborícola como as espécies de Crotophaga Linnaeus, 1758, Guira Lesson, 1831, Tapera Thumberg, 1819 e Dromococcyx Wied, 1832 e há aqueles 
predominantemente arborícolas. Os terrícolas, como as espécies de Carpococcyx Gray, 1840, Coua Cuvier, 1817, Centropus Illiger, 1811, Geococcyx, Neomorphus Gloger, 1827 e Morococcyx Lesson, 1842 são basais, em menor número, de maior porte (220 a 700 g) e se deslocam em curtas distâncias (Wyluie 1981, Hughes 1996, 2000). No entanto dentro de Centropus e Coua há também algumas espécies semi-arborícolas (PAYNE 1997). Já os cucos arborícolas (Cuculidae) são de menor porte (10-100 g), amplamente distribuídos e alguns são capazes de migrar por longas distâncias, como é o caso de algumas espécies de Coccyzus e Cuculus (Wyllie 1981, PAyne 1997).

De acordo com Woodbury (1998), os cucos exibem uma condição primitiva da medula espinhal (assim como as aves Paleognatas), pertencendo a uma das mais antigas linhagens de aves Neognatas. Os registros fósseis indicam uma possível origem no Hemisfério Norte após o Paleoceno, exceto por aquele descrito por BAIRD \& VICKERs-Rich (1997) que descreve um fóssil do Paleoceno do Brasil. A maioria dos autores (Cracraft 1973, Payne 1997, Sick 1997, Hughes 2000) sugere que, em virtude de estarem concentrados nas regiões tropicais e pouco adaptados a climas mais frios (NorRis \& Elder 1982), os cucos devem ter se originado no Hemisfério Sul, particularmente no Velho Mundo.

A classificação dos Cuculiformes sofreu inúmeras alterações desde o início do século XX, e mesmo com vários estudos atuais utilizando morfologia (Hughes 2000, Posso \& Donatelli 2001), comportamento e ecologia (HUGHES 1996) e dados moleculares (Brush \& Witt 1983, Sibley \& Ahlquist 1990. Aragón et al. 1999, Johnson et al. 2000, PAYNe \& SOREnson 2005) ainda hoje permanecem dúvidas e divergências em relação ao relacionamento dos cucos com outras aves. Morfologicamente os cucos têm sido relacionados aos Musophagidae (tauracos, aves frugívoras endêmicas da África), e tradicionalmente estão colocados na mesma ordem Cuculiformes (Peters 1940, Payne 1997, Howard \& Moore 1998). Alguns trabalhos também inserem a cigana Opisthocomus hoazin Muller, 1776, espécie endêmica da América do Sul, dentro dos cucos (Sibley \& Ahlquist 1990) ou próxima a eles (Hughes 2000). Todavia, atuais estudos cladísticos que avaliaram os grupos de aves em geral (Cracraft 1981, Mindell et al. 1997, Livezey \& Zusi 2001, JoHANSSON et al. 2001) indicam que os cucos são altamente apomórficos e, conseqüentemente, de relações incertas com outros grupos de Aves, inclusive em relação aos Musophagidae e O. hoazin.

Entretanto, as maiores divergências se concentram dentro da família. Muitos estudos sobre a filogenia do grupo foram realizados recentemente (Hughes 1996, 2000, PAYNe 1997, Aragón et al. 1999, Johanson et al. 2000, PAYNe \& SOREnson 2005). Todavia, persistem ainda divergências em vários níveis categóricos.

Estas divergências demonstram a necessidade de novos estudos para fornecer hipóteses que possam contribuir para a filogenia deste controverso grupo de aves. Desse modo, este estudo apresenta uma análise filogenética com o maior número de caracteres e táxons já amostrados para este grupo.

\section{MATERIAL E MÉTODOS}

Primeiramente, foram estudados o crânio e mandíbula de 562 espécimes pertencentes a 80 espécies incluídas em 34 gêneros, abrangendo cerca de $85 \%$ dos gêneros atribuídos aos Cuculiformes $(\mathrm{n}=41)$, sensu Howard \& MOORe (1998), adicionando-se Соссусиа Lesson, 1831. Os gêneros ausentes são: Taccocua Lesson, 1831, Scythrops Lathan, 1790, Pachycoccyx Cabanis, 1882, Rhamphomantis Gray, 1858, Cercococcyx Cabanis, 1882, Caliechthrus Blyth, 1846 e Microdynamis Salvador, 1878. Entretanto, com a inclusão dos resultados com base em comportamento e dados ecológicos de Hughes (1996) e de Hughes (2000) com base em osteologia, pode-se adicionar na análise os gêneros Scythrops e Pachycoccyx (conforme matriz, Apêndice 3).

Para comparação da osteologia craniana foram estudados 77 espécimes de Musophagidae representando todos os gêneros existentes $(n=6)$, um espécime de cada espécie $(n=3)$ representando cada família de Anseriformes e 46 espécimes de 11 espécies incluídas em seis gêneros de Cracidae (Galliformes).

Todos estes espécimes já se encontravam previamente preparados (crânios e mandíbulas secos) e fazem parte das coleções de vários museus de história natural que constam nos agradecimentos. A lista dos espécimes utilizados encontra-se no Apêndice 1.

Quanto à nomenclatura utilizada para a descrição da osteologia (terminologia óssea) seguiu-se a proposta pela Nomina Anatomica Avium (Osteologia: BAUMEL \& WiTMER 1993).

Muitos caracteres multiestados foram codificados como binários para torná-los mais objetivos, evitar um número excessivo de estados de um mesmo caráter e minimizar os erros durante o estabelecimento das homologias primárias (BARRIEL $\&$ TASSI 1993), tomando-se o cuidado para que, quando divididos em caracteres binários, não fossem repetidos na matriz.

Por haver controvérsias sobre se Musophagidae realmente é o grupo mais próximo (Livezey \& Zusi 2001) e se é mais basal (PAYNe 1997) em relação aos cucos, optou-se por utilizar um outro grupo externo que a literatura apontasse como provavelmente basal em relação aos cucos. Dessa forma, foram escolhidos os Galloanserimorphae (Galliformes e Anseriformes) que a maioria dos autores aponta como os mais basais dentre as aves Neognatas (Cracraft 1988, Mindell et al. 1997, Sibley \& Ahlquist 1990, Van Tuinen et al. 2000, Livezey \& Zusi 2001).

O cladograma foi obtido através da metodologia da sistemática filogenética por meio do Princípio da Parcimônia utilizando-se do programa PAUP 4.0, versão beta 10 (SwOFFoRd 2001). A análise de seqüência aditiva escolhida foi a randômica ("random additive sequence") utilizando o algoritmo "hsearch" com um número de 1000 árvores. Ainda, utilizou-se o algoritmo "tree-bisection-reconection branch swapping". Foram atribuídos pesos iguais para todos os caracteres. Todos os caracteres multiestados foram considerados previamente ordenados. Como houve cladogramas conflitantes entre si e com o mesmo número de passos, optou-se pelo uso da árvore de consenso

Revista Brasileira de Zoologia 23 (3): 608-629, setembro, 2006 
estrito (definido por Sokal \& Rohlf 1981 apud Kitching et al. 1998).

Para a otimização dos caracteres foi utilizado o algoritmo ACCTRAN e como índice de suportes dos clados a análise "Bootstrap" com um número mínimo de 100 repetições.

Além dos caracteres da osteologia craniana obtidos por direta comparação entre os táxons, utilizaram-se alguns caracteres do crânio $(28,79,80,81$, Apêndice 3$)$ e do aparato hiobronquial (caracteres 207 e 208, Apêndice 3) diretamente de Hughes (2000). Posteriormente, foram adicionados dados provenientes da osteologia pós-craniana, comportamento e ecologia encontrados em Hughes (1996, 2000), visando maximizar o número de informações para a inferência filogenética. Os caracteres da osteologia pós-craniana e comportamento e ecologia não estão citados no Apêndice 3. Para verificação destes, deve-se consultar Hughes (1996, 2000).

Foram utilizados, sem modificações, todos os caracteres disponíveis da osteologia pós-craniana em Hughes (2000). No entanto, quanto aos 28 caracteres do comportamento e ecologia (Hughes 1996), seis foram excluídos da análise (caracteres 14, 18, 19, 22, 24 e 27 de Hughes 1996) por serem dependentes do hábito parasita de ninho. Nesse sentido, foi acrescentado e considerado somente um caráter (caráter 250) em relação à existência ou não de parasitismo de ninho. Quanto aos demais caracteres de Hughes (1996), 17 foram utilizados sem alterações e os cincos restantes em parte modificados (caracteres 1 , 3, 6, 7 e 19 de Hughes 1996). Os critérios para tais modificações se seguem no Apêndice 2 .

Na maioria das classificações existentes os cucos são considerados dentro da família Cuculidae, inserida na ordem Cuculiformes, juntamente com Musophagidae (tauracos). SiBLEY \& AHLquist (1990) não consideram cucos e tauracos em um grupo monofilético particular, sendo a ordem Cuculiformes composta somente pelos cucos e a cigana (Opisthocomus hoazin); e, baseando-se na indicação de ampla divergência molecular que apresentaram entre si, dividem a ordem em famílias, ao invés de subfamílias como se encontra nas classificações tradicionais (PETERS 1940, Verheyen 1956, Howard \& Moore 1998) e nas mais atuais (Payne 1997, Aragón et al. 1999, Johnson et al. 2000, Hughes 2000).

Assim como em Sibley \& Ahlquist (1990), optou-se por considerar os cucos dentro de uma ordem própria (Cuculiformes), composta por várias famílias, por apresentarem longa história evolutiva inferida por relógios moleculares (Sibley \& Ahlquist 1990, Aragón et al. 1999, Johanson et al. 2000) e caracteres plesiomórficos (WoodBury 1998); ampla variação nos hábitats ocupados e distribuição geográfica (PAYNe 1997); e conspícua heterogeneidade nos ossos, plumagem, comportamento, DNA, itens alimentares explorados e estratégias reprodutivas (Shufeldt 1901, Sibley \& Ahlquist 1990, Hughes 1996, 2000, Payne 1997, Aragón et al. 1999, Johnson et al. 2000).

Assim, a nomenclatura para as espécies e classificação é aquela apresentada por Sibley \& Ahlquist (1990), exceto para Соссусиа minuta Lesson, 1831.

\section{RESULTADOS E DISCUSSÃO}

Foram considerados 250 caracteres (matriz, Apêndice 3): 154 caracteres da osteologia craniana (Apêndice 2), 76 (155 a 230) da osteologia pós-craniana (Hughes 2000) e 20 (231 a 250) do comportamento e ecologia (Hughes 1996) onde se incluem Pachycoccyx e Scythrops.

A análise cladística com base nestes caracteres (matriz 1, Apêndice 4) resultou em 18 árvores igualmente parcimoniosas, todas apresentando 765 passos evolutivos mínimos. O Índice de Consistência geral (IC) foi de 0.4779 , o Índice de Retenção geral (IR) de 0.8080 e o Índice de Consistência Reescalonado geral (ICR) de 0.3861. Conforme a metodologia, optou-se pela apresentação de uma única árvore de consenso estrito (Fig. 1).

A análise cladística indica um nível considerado alto de homoplasias (cerca de 52\%: IC $=0.4779$ ). Isto se explica pelo número elevado de táxons terminais, pois quanto maior o número de táxons terminais, menor o Índice de Consistência (Kitching et al. 1998). Todavia, outro motivo é a notável heterogeneidade quanto à morfologia nos cucos. Esta heterogeneidade, provavelmente se deve a, pelos menos, dois fatores históricos atuando em conjunto: a) longa história evolutiva: os cucos são uma das famílias mais antigas dentre as Neoaves (Sibley \& Ahlquist 1990, Woodbury 1998, VAn Tuinem et al. 2000, Johnson et al. 2000) e; b) ampla distribuição geográfica: os cucos são cosmopolitas (PAYNe 1997) com maior diversidade nos trópicos, ocupando diferentes continentes e ilhas e adaptados aos mais diferentes tipos de hábitats (Hughes 1996).

A classificação mais utilizada para os cucos é ainda a de Peters (1940). O cladograma aqui obtido não corrobora o monofiletismo dos grandes grupos tradicionais de cucos de Peters (1940), com exceção de Cuculidae e Crotophagidae (Fig. 1). Isto certamente é reflexo da metodologia distinta aplicada (cladística) em relação àquela que Peters (1940) dispunha na época (similaridade morfológica).

O cladograma (Fig. 1) difere em relação aos dados moleculares (Sibley \& AHLQUist 1990, ARAGÓN et al. 1999, JohNSON et al. 2000) principalmente em relação ao posicionamento dos cucos terrícolas e de maneira geral somente divergem de dados osteológicos de Hughes (2000) em relação ao posicionamento de Tapera e Dromococcyx e sobre o monofiletismo de Phaenicophaeidae.

\section{Monofiletismo da ordem Cuculiformes}

Conforme exposto nos métodos, entende-se aqui por Cuculiformes somente os cucos (sensu Sibley \& AHLquist 1990), excluindo, portanto, a cigana (Opisthocomus hoazin).

Com base nos resultados, conseguiu-se relacionar 98 caracteres (Apêndice 5, ramo 1) que reúnem os Cuculiformes, sendo 48 deles relativos à osteologia craniana, 44 à osteologia pós-craniana e seis à ecologia e comportamento. No entanto, não se pode afirmar que se trata de sinapomorfias exclusivas para os Cuculiformes, uma vez que não se compara com as demais Neoaves, o que foge do escopo deste trabalho. De qual- 


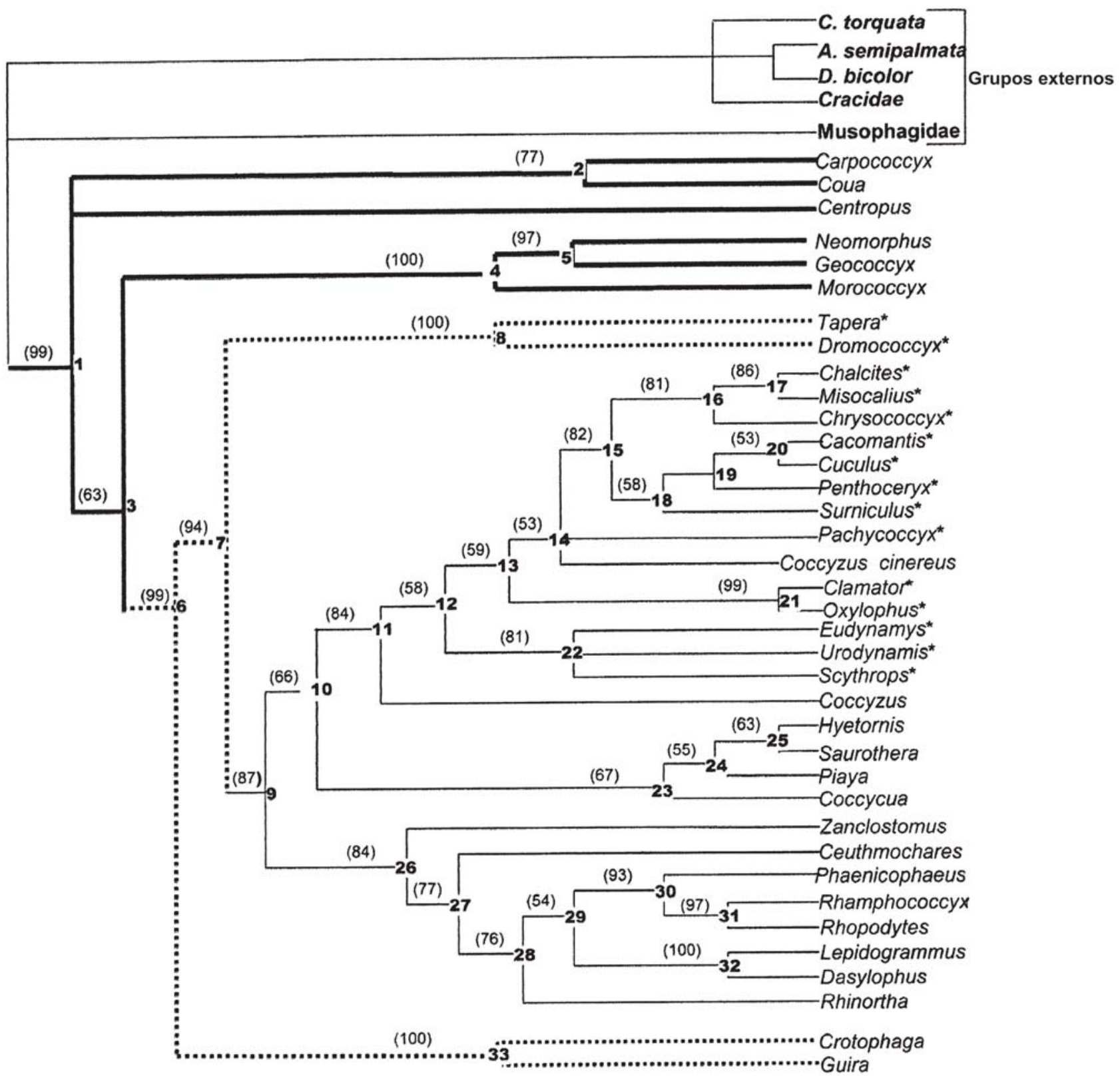

Figura 1. Relações filogenéticas entre os gêneros de Cuculiformes, com base na osteologia, comportamento e ecologia aplicados na analise cladística. Linha espessa: cucos terrícolas; linha pontilhada: transição terrícola/arborícola; linha fina: cucos arborícolas; asterisco: parasitas de ninho; 1-33: ramos para indicar sinapomorfias e para a classificação; (50-100): Índice Bootstrap (onde não há numeração o índice é menor que 50\%).

quer modo, o monofiletismo dos cucos é consenso entre os pesquisadores (Hughes 1996, 2000, Payne 1997, Aragón et al. 1999, JoHnson et al. 2000).

De acordo com o cladograma e muito próximo de Hughes (2000), os Cuculiformes formam dois grupos distintos: a) Carpococcyx e Coua e b) Neomorphidae, Crotophagidae, Taperal
Dromococcyx, e Cuculidae. No entanto, a posição filogenética de Centropus é ambígua, como se discute posteriormente.

Gêneros basais: Carpococcyx e Coua (internó 2)

O parafiletismo entre os cucos predominantemente terrícolas (Carpococcyx, Coua, Centropus e Neomorphidae) é discor-

Revista Brasileira de Zoologia 23 (3): 608-629, setembro, 2006 
dante dos resultados obtidos por Verheyen (1956) que encontrou várias similaridades anatômicas entre estes grupos, e em alguns trabalhos filogenéticos recentes (ARAGón et al. 1999, JoHnson et al. 2000) onde se consideram os cucos terrícolas mais próximos entre si.

Payne (1997) critica a maior proximidade entre os cucos predominantemente terrícolas, pois tais táxons podem ter sido agrupados por convergência por compartilharem este mesmo hábito. Entretanto, o parafiletismo entre estes grupos aqui tem origem em outro fator: o elevado número de simplesiomorfias entre os cucos terrícolas. Assim como em Hughes (2000), os caracteres indicam claramente que se trata de grupos basais, corroborados por vários caracteres plesiomórficos, principalmente em relação ao lacrimal, ectetmóide e mandíbula. Outra resistência em se aceitar o monofiletismo dos cucos terrícolas se encontra no fato de estarem geograficamente distantes (PAYNE 1997) sendo os Neomorphidae endêmicos do Neotrópico, Centropus na África, Madagascar e sul da Ásia, Coua endêmico de Madagascar e Carpococcyx do sul da Ásia.

Dentro do internó 2 observa-se a maior proximidade entre Carpococcyx e Coua. Até a publicação de Verheyen (1956), Carpococcyx era considerado próximo de Neomorphidae e Coua dos cucos do Velho Mundo (Cuculidae e Phaenicophaeidae) (Peters 1940). No entanto, as primeiras análises cladísticas (Hughes 1996, 2000) corroboraram VERHEYEN (1956) onde Carpococcyx está mais próximo de Centropus e Coua e estes foram considerados basais em relação aos demais cucos. Sibley \& AHLQUisT (1990) consideram Carpococcyx e Coua incluídos em Cuculidae e Centropus em Centropodidae. Já Payne (1997) consideram Carpococcyx e Coua incluídos nos "Phaenicophaeinae" e Centropus em uma subfamília à parte ("Centropodinae"), sendo ambas as subfamílias próximas aos "Cuculinae".

Em Hughes (1996) Centropus é considerado mais próximo de Carpococcyx. Hughes (2000) não encontra suporte para o monofiletismo do grupo e sugere que Coua e Centropus estejam mais próximos dos demais cucos e que Carpococcyx é basal e grupo irmão de todos os demais cucos.

O cladograma indica Coua e Carpococcyx como os cucos mais basais e monofiléticos (internó 2). Outro motivo para considerá-los em uma subordem à parte se refere ao longo tempo de cladogênese que apresentam, verificado por meio da análise molecular (JoHNSON et al. 2000).

\section{Centropodidae: o gênero Centropus (incertae sedis)}

Centropus caracteriza-se como um dos gêneros com maior número de autapomorfias (14) no crânio e mandíbula dentre todos os cucos. Isto provavelmente é resultado de um grande número de espécies que possui e à ampla distribuição geográfica. Estes dados corroboram Sibley \& Ahlquist (1990) e PAYNe (1997) que consideram Centropus em um grupo particular, respectivamente Centropodidae e Centropodinae.

Entretanto, suas relações dentro da ordem são incertas. Em estudos onde se inclui este gênero, observa-se maior proximidade com Carpococcyx e Coua (Sibley \& Ahlquist 1990, Hughes
1996, Payne \& Sorenson 2005) ou mais próximos dos demais cucos (Hughes 2000). Esta última observa que a maioria das similaridades deste gênero com os Coua e Carpococcyx são simplesiomorfias quando se estabelece polaridade. O cladograma (Fig. 1) resultou em uma politomia (árvore de consenso estrito) em relação à posição de Centropus, o que gerou incertezas sobre o posicionamento deste gênero com os demais da ordem Cuculiformes.

\section{Neomorphidae}

Neomorphidae é uma das famílias mais controversas sistematicamente dentre os Cuculiformes. Nas classificações tradicionais (Peters 1940), Carpococcyx está incluído dentro de "Neomorphinae". Todavia, nas mais recentes (Hughes 2000, PAyne \& SORENSON 2005) e nos resultados aqui apresentados Carpococcyx não pertence a Neomorphidae.

Segundo Verheyen (1956) e Sibley \& Ahlquist (1990) Neomorphidae é composta por Tapera, Morococcyx, Geococcyx, Dromococcyx e Neomorphus, sendo que o último autor os separa em duas subfamílias distintas: Neomorphinae (Geococcyx, Neomorphus e Morococcyx) e Taperinae (Tapera e Dromococcyx).

Estudos moleculares atuais (Sibley \& Ahlquist 1990, PAyne 1997, Aragón et al. 1999, Johnson et al. 2000, Payne \& Sorenson 2005) indicam que Neomorphidae é um grupo monofilético, próximo dos demais cucos terrícolas. Todavia, estudos anatômicos (Hughes 2000), comportamentais e ecológicos (Hughes 1996) sugerem que Neomorphidae seja parafilético, uma vez que Tapera e Dromococcyx estão mais próximos dos cucos do Velho Mundo (Cuculidae).

Hughes (2000: 296) utilizou-se de alguns caracteres osteológicos cranianos e encontrou somente duas características cranianas semelhantes entre Tapera e Dromococcyx e as demais espécies de Neomorphinae: "U shape of the hiatus subtympanicus" (caráter 40) e "U shape of the caudal surface of the os articulare" (caráter 51) e as considera convergências adaptativas, relacionadas ao hábito alimentar.

Em Hughes (2000) há oito características ósseas cranianas (caracteres 4, 5, 24, 31, 33, 34, 37 e 45) similares entre Taperal Dromococcyx e "Cuculinae", "Coccyzinae" e "Phaenicophaeinae". Concordou-se com Hughes somente em relação à primeira característica, que se refere ao estreitamento entre as margens do osso frontal (Apêndice 3, caráter 8).

Quando se faz uma análise com diferentes tipos de caracteres (Fig. 1), pesam a favor os caracteres da osteologia póscraniana para o agrupamento de Tapera e Dromococcyx com cucos parasitas de ninho (Cuculidae). Como resultado, estes dois gêneros estão mais próximos deste grupo (internó 7).

Desse modo, resta somente as relações filogenéticas entre os demais Neomorphidae (sensu Sibley \& AHLquist 1990) aqui composta por Geococcyx, Morococcyx e Neomorphus (internó 4). Estes gêneros aparecem reunidos praticamente em todas as classificações existentes, portanto, pouca divergência existe sobre seu monofiletismo. Estes três gêneros se distribuem principalmente pelo norte da região Neotropical, chegando a ocorrer na 
região Neártica, como é o caso de Geococcyx californianus (Lesson, 1829) (Payne 1997). Geococcyx e Neomorphus (internó 5) formam um grupo irmão com Morococcyx. Em um estudo com caracteres morfológicos externos e comportamentais, Haffer (1977) menciona que Neomorphus e Geococcyx são mais similares entre si do que com quaisquer outros cucos.

O grande agrupamento (internó 6) dos cucos semiarborícolas (Crotophagidae e Tapera e Dromococcyx) e arborícolas (Coccyzidae e Cuculidae) é considerado monofilético somente após as análises cladísticas recentes onde se utilizam caracteres anatômicos (Hughes 2000: 10 sinapomorfias). Crotophagidae, Tapera e Dromococcyx (internós 8 e 33, respectivamente) são considerados os mais basais do grupo, ocorrem na América do Sul e apresentam ainda, mesmo que parcialmente, hábitos terrícolas (PAYNe 1997, Sick 1997).

Os Crotophagidae (internó 33) compreendem Guira e Crotophaga e Sibley \& AHLQUisT (1990) os elevam à condição de família (Crotophagidae) dada a grande diversidade genética que apresentaram em relação aos demais cucos. Aparentemente, o nível categórico (família) de Sibley \& AHLQuist (1990) parece ser o mais apropriado para este dois gêneros, por apresentarem elevado número de sinapomorfias (23, Apêndice 5: ramo 33), que indica um longo tempo de cladogênese, evidenciada por várias particularidades não somente na osteologia, mas também nas peculiares estratégias reprodutivas e hábitos alimentares gregários (DAvis 1940a,b, 1942, MACEDo 1992, Souza 1995, Hughes 1996, Payne 1997, Sick 1997, Martins \& Donatelli 2001, Posso \& Donatelli 2001).

A maioria dos recentes trabalhos em filogenia molecular e anatomia (Hughes 2000, Johnson et al. 2000, PAyne \& Sorenson 2005) indicam que Crotophagidae é um grupo monofilético e agrupado com os cucos arborícolas (ramo 9), sendo os mais basais dentro deste grupo, o que é corroborado neste trabalho (Fig. 1) por haver fortes evidências sobre seu monofiletismo e posição basal (Apêndice 5, internó 33). Entretanto, há uma hipótese alternativa recente com base em dados moleculares (PAYNe \& SORENSON 2005) indicando os Crotophagidae mais próximos dos Neomorphidae.

Não obstante, se nota uma ampla variedade de caracteres que distinguem Crotophaga de Guira (matriz 1, Apêndice 4) supondo que provavelmente estes gêneros devam ter se separado há muito tempo. Tal conclusão está de acordo com Sibley \& AHLqUist (1990), que os consideram em duas tribos distintas: Guirini e Crotophagini, dada a grande diversidade genética observada. Ainda, há uma hipótese de relações entre as espécies desta família (Guira guira Lesson, 1831 (Crotophaga major Gmelin, 1788 (Crotophaga ani Linnaeus, 1758 e Crotophaga sulcirostris Swaison, 1827))) em Posso \& Donatelli (2001). Estas relações encontradas na osteologia também são corroboradas em dois estudos recentes com base em dados moleculares (Hughes 2003, Payne \& Sorenson 2005).

Quanto à Tapera e Dromococcyx (internó 8), estes apresentam posicionamentos divergentes na literatura, conforme discutido anteriormente. Aqui, se observam mais próximos dos cucos arborícolas (Cuculidae e Coccyzidae), sendo um dos grupos mais basais deste agrupamento (Fig. 1).

BERGER (1960) supôs parafiletismo para o grupo Tapera/ Dromococcyx, separando Tapera dos outros Neomorphidae, inclusive de Dromococcyx, e agrupando Tapera com os cucos do Velho Mundo (Cuculidae). Entretanto, aqui Tapera forma um grupo claramente monofilético com Dromococcyx (Apêndice 4, ramo 8), concordando com vários autores (Sibley \& AHLQUisT 1990, Hughes 1996, 2000, Payne 1997, Aragón et al. 1999, Payne $\&$ SORENSON 2005).

\section{Os cucos arborícolas (Cuculidae)}

O monofiletismo entre os cucos arborícolas (internó 9) é aqui apoiado por 25 sinapomorfias (Apêndice 4, ramo 9). Ainda, este é um dos raros agrupamentos em que não se apresentam divergências nas análises filogenéticas da literatura.

As classificações tradicionais, refletidas em Peters (1940), consideram Phaenicophaeinae contendo vários gêneros de cucos incluindo aqueles Neotropicais: Cocсусиа, Saurothera Vieillot, 1816, Hyetornis Sclater, 1862, Piaya Lesson, 1831 e Coccyzus e gêneros que ocorrem na região biogeográfica Oriental Rhopodytes Cabanis \& Heine, 1862, Taccocua, Rhinortha Vigors, 1830, Zanclostomus Swaison, 1837, Rhamphococcyx Cabanis \& Heine, 1862, Phaenicophaeus Vieillot, 1816, Dasylophus Swaison, 1837 e Lepidogrammus Reichenbach, 1849 e Etiópica: Ceuthmochares Cabanis \& Heine, 1863. PAYNE (1997) retira os gêneros neotropicais desta família e considera Phaenicophaeinae contendo todos os gêneros que ocorrem no sul da Ásia e Oceania, juntamente com Carpococcyx e Coua. O mesmo se observa em Sibley \& AHLquisT (1990).

Em estudos cladísticos recentes (Aragón et al. 1999, Hughes 2000, Payne \& Sorenson 2005) Phaenicophaeinae (sensu Payne 1997) está mais próximo de Coccyzine que de Cuculine.

Com base principalmente nos caracteres multiestados (Apêndice 4, ramos 9, 10, 11, 12 e 26) nota-se que, dentre os cucos arborícolas, os Phaenicophaeinae são mais basais (internó 26) е Coccycua, Saurothera, Hyetornis e Piaya formam um grupoirmão de Cuculinae (internó 10). É possível que, o que difere os resultados aqui obtidos em relação àqueles encontrados pelos demais autores (ArAgón et al. 1999, Hughes 2000, Payne \& SoRENSON 2005) seja a questão da polaridade. Se somente as similaridades morfológicas forem consideradas, observa-se que Соссусиа, Piaya, Saurothera e Hyetornis e Phaenicophaeidae são semelhantes entre si. Todavia, sob a luz da cladística aplicada aos caracteres osteológicos, a maioria destas semelhanças é considerada simplesiomorfia.

Hughes (2000) considera os "Phaenicophaeinae" (sensu Peters 1940) monofiléticos, exceto por considerar Coccyzus como mais próximos dos "Cuculinae". Entretanto, a validade de "Phaenicophaeinae" é fracamente sustentada nestas análises. Em Hughes (2000) estão suportados somente em 54\% dos cladogramas possíveis. Já outras análises (SIBLEY \& AHLQUIST 1990,

Revista Brasileira de Zoologia 23 (3): 608-629, setembro, 2006 
Hughes 1996, Aragón et al. 1999, Johnson et al. 2000) pouco ou nada informam sobre esta família por não utilizarem suas espécies. Entretanto em PAyne \& Sorenson (2005) há um filogenia englobando todos os gêneros dentro deste grupo e considera agrupados a eles também os Coccyzine, sendo os ramos bem sustentados pela análise de suporte.

Em relação ao presente trabalho, dentro do internó 26, Ceuthmochares e Zanclostomus são grupos-irmãos dos demais gêneros e os mais basais do grupo. O mesmo pode ser observado na análise cladística de Hughes (2000) e Payne \& Sorenson (2005), embora nestas, Ceuthmochares é mais basal também em relação aos Coccyzinae e Cuculinae.

Ainda, os demais gêneros formam um grupo monofilético (internó 28). Payne (1997) prefere agrupá-los todos em um único gênero Phaenicophaeus. Hughes (2000) não utiliza Phaenicophaeus em sua análise e aproxima Rhamphococcyx e Rhopodytes de Lepidogrammus e Dasylophus. Já PAYne \& Sorenson (2005) agrupam Rhamphococcyx e Dasylophus próximo aos Coccyzinae.

Nesta análise e, assim como em PAYne \& Sorenson (2005), as relações de parentesco não são ambíguas para os gêneros e, de acordo com a topologia encontrada e a clara divergência osteológica entre os táxons, estes foram considerados em gêneros à parte e não reunidos em um único gênero como prefere PAYNe (1997).

Rhinortha é basal em relação aos demais gêneros (internó 28), assim como em outras filogenias recentes (Hughes 2000, Payne \& Sorenson 2005).

Assim como em Hughes (2000), os demais gêneros formam um grupo monofilético (internó 29), sendo Rhamphococcyx e Rhopodytes grupo-irmão de Phaenicophaeus (internó 30) e Lepidogrammus e Dasylophus (internó 32) um grupo monofilético à parte, por meio de 19 sinapomorfias (Apêndice 5, ramo 32). Além disso, apresentam plumagem e comportamento semelhantes (Payne 1997). Já para Payne \& Sorenson (2005) estes são agrupamentos parafiléticos.

Соссусиа, Saurothera, Hyetornis, Piaya e Coccyzus são tradicionalmente agrupados em Coccyzidae (Sibley \& Ahlquist 1990). Entretanto, o cladograma indica esta família parafilética, em virtude de Coccyzus estar mais próximo dos Cuculinae. O mesmo é observado em Hughes (1996, 2000).

A análise indica o monofiletismo de quatro gêneros Neotropicais (Saurothera, Hyetornis, Piaya e Coccycua) (internó 23). Em Hughes (2000) o clado Piaya/Hyetornis está bem corroborado (90\% dos cladogramas possíveis). Aqui Hyetornis está mais próximo de Saurothera (interno 25), corroborando a proximidade geográfica entre eles, que são simpátricos em algumas ilhas do Caribe (PAYNe 1997). Estes dois gêneros são grupos-irmãos de Piaya (internó 24) e Сoccycua grupo-irmão de Piaya, Saurothera e Hyetornis (interno 23). Payne \& Sorenson (2005) não contemplam Saurothera e Hyetornis.

Hughes (1996) aproxima Saurothera dos cucos terrícolas, particularmente de Coua, por compartilharem entre si o comportamento terrícola e se alimentarem de invertebrados e ver- tebrados. Todavia, Saurothera encontra-se distantemente relacionado destes gêneros (Fig. 1) como em Hughes (2000), o que indica que tais comportamentos sejam resultantes de convergência entre estes táxons. Fato também observado pela forma semelhante do bico entre Saurothera, Geococcyx e Dromococcyx que muito provavelmente é resultado de convergência entre estes gêneros por ocorrem em hábitats e apresentarem hábitos alimentares semelhantes (Payne 1997, Hughes 2000).

Os gêneros restantes de Cuculidae (internó 11) foram o agrupamento mais politípico dentre os cucos e se distribui por quase todo o planeta, principalmente nas regiões tropicais (PAYNE 1997). Todos são arborícolas e parasitas de ninho obrigatórios (exceto Coccyzus), o que reforça o monofiletismo do grupo. Não obstante, é a família mais derivada dentro dos cucos e seu monofiletismo é fortemente corroborado (Apêndice 5, ramo 11), assim como em outros trabalhos, exceto para Coccyzus (Peters 1940, Verheyen 1956, Sibley \& Ahlquist 1990, Aragón et al. 1999, Johnson et al. 2000, Payne \& Sorenson 2005). Já Hughes (2000) inclui também este gênero neste agrupamento. $\mathrm{Na}$ análise Coccyzus é basal em relação aos demais Cuculidae (internó 11).

Payne \& Sorenson (2005) consideram Coccyzus mais próximos de Piaya e Coccycua, corroborando a família Coccyzidae (sensu Sibley \& AHLquist 1990).

Todavia, embora os crânios de Coccyzus e de Saurothera, Hyetornis, Piaya e Соссусиа sejam semelhantes entre si, estas semelhanças são aqui consideradas simplesiomorfias. BERGER (1960: 94 e 95) encontrou três semelhanças anatômicas entre Coccyzus e Saurothera e Piaya, mas supõe que tais semelhanças, bem como aquelas provenientes da mesma distribuição (Novo Mundo), comportamento e vocalização, não reflitam parentesco e posiciona Coccyzus junto aos demais Cuculidae. Embora Coccyzus preserve semelhanças plesiómorficas com Saurothera, Hyetornis, Piaya e Сoccycua, é aqui sugerido como um táxon mais derivado e pertencente aos Cuculidae.

Hughes (2000) inclui Coccyzus mais próximo de Clamator (Kaup, 1829) e Oxylophus (Swainson, 1837), formando uma tribo denominada Coccygini dentro de Cuculidae. A osteologia craniana aplicada à cladística indica o posicionamento de Coccyzus cinereus (Vieillot, 1817) fora de Coccyzus (internó 14), aparentemente sugerindo um parafiletismo do gênero Coccyzus. No entanto, é necessário analisar outras fontes de caracteres no intuito de corroborar ou refutar este possível parafiletismo para o gênero. Desse modo, a validade do gênero Coccyzus será discutido em uma publicação posterior.

As relações entre os três gêneros que compõem o internó 22 não foram resolvidas (politomia) em virtude de não se utilizar Scythrops para os caracteres da osteologia (matriz, Apêndice 4). Eudynamys (Vigors \& Horsfield, 1827) e Urodynamis (Salvadori, 1880) são considerados pela maioria dos autores como gêneros monoespecíficos. Entretanto, em PAYNe (1997) Urodynamis é considerado dentro do gênero Eudynamys (E. taitensis). Já PAYNe \& Sorenson (2005) consideram este gêneros distantemente relacionados. 
A análise cladística indica monofiletismo para estes gêneros, entretanto diferem consistentemente entre si por meio de 23 autapomorfias (não descritas na análise) que se referem à osteologia craniana. Não há paralelo de tal divergência morfológica craniana entre espécies congêneres de cucos, nem sequer entre gêneros próximos. Portanto, além do monofiletismo, a osteologia craniana indica estes dois táxons como gêneros distintos: Eudynamys e Urodynamis. Eudynamys é bem distribuído pelo sul da Ásia, desde a Índia até o extremo Sudeste e também por toda a Oceania, com exceção das pequenas ilhas ao leste, onde se encontra Urodynamis (PAYNe 1997). Este isolamento insular de Urodynamis, pode ter sido um dos fatores que ocasionou maior taxa de diferenciação morfológica em relação a Eudynamys.

Historicamente Clamator e Oxylophus estão próximos entre si (Shelley 1891, Peters 1940). Aqui o monofiletismo destes gêneros é bem suportado (internó 21) e é grupo-irmão basal dos demais Cuculidae. O mesmo se observa em Hughes (2000). Já em Aragón et al. (1999) e Payne \& Sorenson (2005), Clamator está mais próximo de Coccyzinae.

Pachycoccyx é posicionado como o táxon mais basal, porém em uma tritomia com os demais Cuculidae e Coccyzus cinereus (internó 14). Entretanto, a análise "Bootstrap" considera Pachycoccyx mais próximo dos demais Cuculinae em 58\% dos cladogramas comparados. No entanto a posição de Pachycoccyx é ainda obscura.

A reunião de Chrysococcyx Boie, 1827, Chalcites (Lesson, 1831) e Misocalius (Cabanis \& Heine, 1876) (internó 16) é também encontrada na análise obtida por vários autores (Sibley \& Ahlquist 1990, Hughes 1996, Aragón et al. 1999, Hughes 2000). Todavia, Payne (1997) e Payne \& Sorenson (2005) os considera dentro de um único gênero, Chrysococcyx. Entretanto, a análise cladística apresenta relações não-ambíguas entre seus táxons e com boa resolução (internós 16 e 17) indicando que pertencem a gêneros distintos. Os gêneros Chalcites e Misocalius estão reunidos (internó 17) por meio de três sinapomorfias (Apêndice 5, ramo 17) e Chrysococcyx forma um grupo-irmão destes dois gêneros (internó 16).

Embora haja um consenso na literatura (ARAGÓN et al. 1999, Hughes 2000, Johnson et al. 2000, Payne \& Sorenson 2005) sobre o monofiletismo de Surniculus Lesson, 1831, Cuculus, Cacomantis S. Müller, 1842 e Penthoceryx (Latham, 1790) (internó 18), nota-se que os caracteres pouco variam entre eles e que apresentam os caracteres mais derivados dentro da ordem, indicando cladogêneses recentes. Na maioria dos dados moleculares (Sibley \& Ahlquist 1990, ARAgón et al. 1999, JoHnson et al. 2000) muitos dos táxons estão ausentes e pouco se pode comparar com a análise aqui obtida. Entretanto em PAyNe \& SORENSON (2005) observa-se Cacomantis grupo-irmão do agrupamento Cuculus/Surniculus.

Aqui Surniculus é grupo-irmão dos demais e Cacomantis está mais próximo de Cuculus que de Penthoceryx (internó 20). Penthoceryx está relativamente distante de Cacomantis, justifi- cando a validade do gênero, pois muitos autores consideram $P$. sonneratti (Latham, 1790) como Cacomantis sonneratti.

\section{Evolução do parasitismo de ninho e a transição dos hábi- tos terrícola/arborícola nos cucos}

Um dos assuntos mais controversos em relação aos cucos se refere ao surgimento do parasitismo de ninho e à transição entre os hábitos arborícola e terrícola, uma vez que podem ter surgido respectivamente, no mínimo duas, e uma vez independentemente nesta ordem (PAYNe 1997, Sick 1997, Aragón et al. 1999) ou admite-se somente um surgimento de parasitismo e dois surgimentos do hábito terrícola (Hughes 1996, 2000).

O consenso sobre as relações filogenéticas de Tapera e Dromococcyx com os demais cucos são cruciais para se estabelecer o padrão evolutivo de parasitismo de ninho e a transição entre os hábitos arborícolas e terrícolas apresentados pelos cucos, em virtude de ambos os gêneros apresentarem posições filogenéticas controversas quando se comparam os estudos sistemáticos recentes (Sibley \& Ahlquist 1990, Payne 1997, Aragón et al. 1999, Hughes 2000, JoHnson et al. 2000) e por serem parasitas de ninho e apresentarem uma condição intermediária entre os hábitos terrícolas/arborícolas.

Os cladogramas com base na osteologia (HugHes 2000) indicam somente um aparecimento do parasitismo de ninho, aproximando os parasitas de ninho Neotropicais (Tapera, Dromococcyx e Coccyzus, este parasita parcial) daqueles do Velho Mundo (Cuculidae). No entanto dados moleculares indicam pelo menos dois surgimentos independentes (Aragón et al. 1999, Payne \& Sorenson 2005), pois Tapera e Dromococcyx estão mais próximos de cucos não parasitas (Neomorphidae).

No cladograma, Tapera e Dromococcyx são basais de um grande grupo de cucos (internó 7), nos quais se incluem cucos mais basais e não parasitas de ninho e os mais derivados e parasitas de ninho. Isto indica que o parasitismo de ninho ocorreu, no mínimo, duas vezes independentemente nos cucos: uma em Tapera e Dromococcyx (internó 8) e outra nos Cuculidae mais derivados (internó 11).

Ainda, dentre as espécies de Coccyzus, C. americanus (Vieillot, 1811) e C. erythrophthalmus Bonaparte, 1824 parasitam ninhos de outras aves em algumas ocasiões e em outras constroem ninhos onde depositam seus ovos (PAyne 1997). Hughes (2000) admite uma perda parcial secundária do comportamento de se parasitar ninhos em Coccyzus. Aqui Coccyzus se apresenta como o táxon mais basal dentre os parasitas de ninho (internó 11). Isto sugere que não deve ter perdido secundariamente este hábito conforme sugeriu HugHEs (2000) e sim, representaria a transição entre o hábito de cuidar da própria prole e parasitar ninhos, o que devia ser o caso no ancestral dos Cuculidae (internó 11).

Já em relação ao hábito terrícola, dados moleculares de Aragón et al. (1999) indicam que os cucos terrícolas (Neomorphidae, Centropodidae e Crotophagidae) formam um grupo monofilético, embora as análises "Bootstrap" indiquem

Revista Brasileira de Zoologia 23 (3): 608-629, setembro, 2006 
que este clado não é robusto. Entretanto outro estudo utilizando dados moleculares (PAYne \& Sorenson 2005) indica Centropus, Coua e Carpococcyx mais próximos dos cucos arborícolas. Hughes (2000) embora observe que o hábito terrícola é basal e o arborícola derivado, considera que o hábito terrícola teria surgido duas vezes independentemente neste grupo: uma em Tapera e Dromococcyx e outra nos cucos terrícolas.

Entretanto, aqui Tapera e Dromococcyx apresentam-se como táxons intermediários e que, juntamente com os Crotophagidae, parecem demonstram a transição entre estes dois hábitos. Crotophaga, Guira, Tapera e Dromococcyx, embora pertençam ao mesmo grupo dos cucos arborícolas (internó 6) são considerados basais em relação à estes e apresentam uma transição entre estes dois hábitos pois forrageiam no chão, porém utilizam as árvores para construção ou parasitismo de ninhos (PAYNE 1997, Sick 1997). Já os cucos predominantemente arborícolas (Cuculidae) são monofiléticos e derivados, atestado pelas polaridades de vários caracteres (Apêndice 5, ramo 9).

De acordo com a filogenia aqui proposta, os cucos terrícolas são parafiléticos (Fig. 1), pois Neomorphidae, Crotophagidae e Tapera e Dromococcyx parecem estar mais próximos dos cucos arborícolas que dos demais terrícolas (Coua e Carpococcyx).

Assim, o hábito terrícola teria surgido uma única vez e no início da evolução dos cucos, sugerindo que o hábito terrestre seja basal, assim como notaram Shufeldt (1909) e Hughes (2000) e como está implícito nas análises moleculares (ARAGÓN et al. 1999, Johnson et al. 2000, Payne \& Sorenson 2005). Desse modo, provavelmente o ancestral cuculídeo era terrícola e este hábito permaneceu nos cucos mais basais (Carpococcyx, Coua, Centropus, Geococcyx, Neomorphus e em Morococcyx).

Vale lembrar que algumas espécies de Centropus e Coua não são exclusivamente terrícolas (PAYNE 1997). Todavia, como o hábito terrícola parece ser um comportamento basal, a condição semi-arborícola deve ter ocorrido secundariamente na evolução das espécies deste gêneros, indicando uma convergência adaptativa em relação aos demais cucos que habitam árvores.

\section{AGRADECIMENTOS}

Aos membros da banca de defesa de Doutorado, professores(as) Elizabeth Höfling, Nelson Bernardi, Luís F. Silveira e Herculano M. Ferraz Alvarenga, que muito contribuíram para melhorar este trabalho. Ao Instituto de Biociências da USP de São Paulo que permitiu realizar o Doutorado do primeiro autor e que resultou neste trabalho. Aos curadores e funcionários dos seguintes museus pelos empréstimos do material e/ou por permitir o estudo do mesmo in loco: Museu Paraense Emílio Goeldi (MPEG) Belém, Brasil; Museum of Vertebrate Zoology (MVZ), University of California, Berkeley, EUA; Museum of Zoology, University of Michigan (UMMZ), Ann Arbor, EUA; National Museum of Natural History (USNM), Smithsonian Institution, Washington, DC, EUA; Field Museum of Natural History (FMNH), Chicago, EUA; American Museum of Natural History (AMNH),
Nova York, EUA; Museu de História Natural de Taubaté (MHNT), Taubaté/SP, Brasil e Laboratório de Vertebrados (LV) da UNESP, Bauru/SP. Ainda, a FAPESP (Processo 99/08000-0) pela ajuda financeira conferida ao primeiro autor.

\section{REFERÊNCIAS BIBLIOGRÁFICAS}

Aragón, S.; A.P Moller; J.J. Soler \& M. Soler. 1999. Molecular phylogeny of cuckoos supports a polyphyletic origin of brood parasitism. Journal of Evoutionary Biology, Oxford, 12: 495-506.

BAIRD, R.F. \& R.P. VICKERS-RICH. 1997. Eutreptodactylus itaboraiensis gen. et sp. nov., an early cuckoo (Aves: Cuculidae) from the Late Paleocene of Brazil. Alcheringa, Sydney, 21: 123-127.

BARRIEL, V. \& P. TASSI. 1993. Characters, observations and steps: comment on Lipscomb's parsimony, homology and the analysis of multistate characters. Cladistics, New York, 9: 223-232.

Baumel, J. \& L. M. Witmer. 1993. Osteologia, p. 45-132. In: J. Baumel; A.S. King; J.E. Breazile; H.E Evans \& J.C. Vanden Berge (Eds). Handbook of Avian Anatomy: Nomina Anatomica Avium. Cambridge, Nuttall Ornithological Club (23), $\mathrm{XXIII+779p.}$

Berger, A.J. 1960. Some anatomical characters of the Cuculidae and the Musophagidae. The Wilson Bulletin, Lawrence, Kansas, 72: 60-140.

BRUSH, A.H. \& H.H. WITT. 1983. Intraordinal relationships of the Pelecaniformes and Cuculiformes: electrophoresis of feather keratins. The Ibis, London, 125: 181-199.

Cracraft, J. 1973. Continental drift, paleoclimatology, and the evolution and biogeography of birds. Journal of Zoology, London, 169: 455-545.

Cracraft, J. 1981. Toward a phylogenetic classification of the recent birds of the world (Class Aves). The Auk, Washington, 98 (1): 681-714.

Cracraft, J. 1988. The major clades of birds, p. 339-361. In: M.J. BENTON (Ed.). The phylogeny and classification of the tetrapods: amphibians, reptiles, birds. Oxford, Claredon Press, Systematic Association, vol. 1, XXXV+378p.

DAvIs, D.E. 1940a. Social nesting habits of the Smooth-billed Ani. The Auk, Washington, 57: 179-218.

DAvIs, D.E. 1940b. Social nesting habits of Guira guira. The Auk, Washington, 57: 472-484.

DAVIS, D.E. 1942. The phylogeny of social nestling habits in the Crotophaginae. The Quarterly Review of Biology, Chicago, 17: 115-134.

Davies, N.B. 2000. Cuckoos, Cowbirds and other Cheats. London, T. \& A.D. Poyser, 312p.

Davies, N.B. \& M.L. BRooke. 1988. Cuckoos versus reed warblers: adaptations and counteradaptations. Animal Behavior, Bloomington, 36: 262-284.

DAVIES, N.B. \& M.L. BRooKe. 1989a. An experimental study of coevolution between the cuckoo Cuculus canorus and its hosts. Part 1: Host egg discrimination. Journal of Animal 
Ecology, London, 58: 207-224.

Davies, N.B. \& M.L. Brooke. 1989b. An experimental study of coevolution between the cuckoo Cuculus canorus and its hosts. Part 2: Host egg discrimination. Journal of Animal Ecology, London, 58: 225-236.

Feduccia, A. 1996. The origin and evolution of birds. New Haven \& London, Yale University Press, I+466p.

Haffer, J. 1977. A systematic review of the Neotropical groundcuckoos (Aves, Neomorphus). Bonner Zoologische Beiträge, Bonn, 28 (1): 48-76.

Howard, R. \& A. Moore. 1998. A complete checklist of the birds of the world. London, Academic Press, II+630p.

Hughes, J.M. 1996. Phylogenetic analysis of the Cuculidae (Aves, Cuculiformes) using behavioral and ecological characters. The Auk, Washington, 113 (1): 10-22.

Hughes, J.M. 2000. Monophyly and phylogeny of cuckoos (Aves, Cuculidae) inferred from osteological characters. Zoological Journal of the Linnean Society, London, 130: 263-307.

Hughes, J.M. 2003. Phylogeny of cooperatively breeding cuckoos (Cuculidae, Crotophaginae) based on mitochondrial gene sequences. Naturwissenschaften, Leipzig, 90 (5): 231-233.

Johnson, K.P; S.M. Goodman \& S.M. Lanyon. 2000. A phylogenetic study of the Malagasy Couas with insights into cuckoo relationships. Molecular Phylogeny and Evolution, Ann Arbor, 14 (3): 436-444.

Johansson, U.S.; T.J. Parsons; M. Irestedt \& G.P. Ericson. 2001. Clades within the "higher land birds", evaluated by nuclear DNA sequences. Journal of Zoological Systematics and Evolutionary Research, Berlin, 39: 37-51.

Kitching, I.J.; P.L. Forey; C.J. Humphries \& D.M. Williams. 1998. Cladistics: The theory and practice of parsimony analysis. New York, Oxford University Press, II+228p.

Krüger, O. \& N.B. Davies. 2002. The evolution of cuckoo parasitism: a comparative analysis. Proceedings of the Royal Society of London B, London, 269: 375-381.

Livezey, B.C. \& R.L. Zusi. 2001. Higher-order phylogenetics of modern Aves based on comparative anatomy. Netherlands Journal of Zoology, Leiden, 51 (2): 179-205.

Macedo, R.H. 1992. Reproductive patterns and social organization of the communal guira cuckoo (Guira guira) in Central Brazil. The Auk, Washington, 109 (4): 786-799.

Martins, F.C. \& R.J. Donatelli. 2001. Estratégia alimentar de Guira guira (Cuculidae, Crotophaginae) na região centro-oeste do Estado de São Paulo. Ararajuba, Londrina, 9 (2): 89-94.

Mindell, D.P.; M.D. Sorenson; C.J. Huddleston; H.C. Miranda JR.; A. Knight; S.J. Swachuk \& T. Yuri. 1997. Phylogenetic relationships among and within select avian orders based on mitochondrial DNA, p. 213-247. In: D.P. Mindell (Ed.). Avian Molecular Evolution and Systematics. San Diego, California Academic Press, I+382p.
NorRIS, D.J. \& W.H. Elder. 1982. Decline of the Roadrunner in Missouri. The Wilson Bulletin, Lawrence, 94: 354-355.

PaYne, R.B. 1974. The evolution of clutch size and reproductive rates in parasitic cuckoos. Evolution, Lawrence, 28: 169181.

Payne, R.B. 1997. Order Cuculiformes, p. 508-607. In: J. Del Hoyo; A. Elliott \& J. Sargatal (Eds). Handbook of the birds of the world. Barcelona, Lynx Editions, IV+674p.

Payne, R.B. \& M.D. Sorenson. 2005. A molecular genetic of cuckoo phylogeny, p. 68-94. In: R.B. PAYNe (Ed.). The cuckoos. Oxford, University Press, 610p.

Peters, J.L. 1940. Checklist of birds of the world. Cambridge, Museum of Comparative Zoology, XI+401p.

Posso, S.R. \& R.J. Donatelli. 2001. Cranial osteology and systematics implications in Crotophaginae (Aves, Cuculidae). Journal of Zoological Systematics and Evolutionary Research, Berlin, 39: 247-256.

Shelley, G.E. 1891. Catalogue of birds in the British Museum. London, British Museum, XIX.

SHufeldt, RW. 1901. The osteology of the cuckoos. Proceedings Annals Phiosophy Society, London, 19: 4-51.

Shufeldt, R.W. 1909. Osteology of birds. Bulletin of the New York State Museum, New York, 130.

Sibley, G.C. \& J.E. AhLQuist. 1990. Phylogeny and classification of birds. New Haven, Yale University Press, I+976p.

SICK, H. 1997. Ornitologia brasileira. Rio de Janeiro, Nova Fronteira, II+862p.

Soler, M.; J.J. Soler; J.G. Martinez \& A.P. Moller. 1994. Microevolutionary change in host response to a brood parasite. Behavioral Ecology and Sociobiology, Heidelberg, 35: 295301.

SouzA, F.L. 1995. A study of group structure and home range size of Crotophaga ani and Guira guira in São Paulo, Brasil (Cuculiformes: Cuculidae). Ararajuba, Brasília, 3: 72-74.

Swofford D.L. 2001. Paup 4.0b10 for 32-bit Microsoft Windows: Phylogenetics analysis using parsimony and other methods. Sunderland, Sinauer.

Van Tuinen, M.; C.G. Sibley \& S. B. Hedges. 2000. The early history of modern birds inferred from DNA sequences of nuclear and mitochondrial ribosomal genes. Molecular Biology and Evolution, Yale, 17: 451-457.

Verheyen, R. 1956. Contribution à l'anatomie et à la systématique des touracos (Musophagi) et des coucous (Cuculiformes). Bulletin of the Institution Royal Scientic Nattural Belgique, Bruxelles, 32 (23): 1-28.

Woodbury, C. J. 1998. Two spinal cords in birds: Novel insights into early avian evolution. Proceedings of the Royal Society of London, Series B, Biological Sciences, London, 265: 1721-1729.

WyLLIE, I. 1981. The cuckoo. New York, Universe Books, I+272p.

Recebido em 01.III.2005; aceito em 03.VIII.2006. 
Apêndice 1. Lista dos espécimes utilizados na análise cladística. Os acrônimos dos museus poderão ser identificadas nos agradecimentos.

Grupo Interno (Cuculiformes)

Couidae: Coua caerulea UMMZ 208404, 209201; Coua cristata Gray, 1829 USNM 432197, 432238, AMNH 10071, 6430, UMMZ 157526; Coua gigas Gray, 1846 FMNH 345635; Coua reynaudii Pucheran, 1845 UMMZ 208403, USNM 223860; Coua ruficeps Gray, 1846 USNM 432195, UMMZ 209203; Coua serriana Pucheran, 1845 AMNH 15925; Carpococcyx radiatus (Gray, 1840) USNM 223970; Carpococcyx renauldi Oustalet, 1896 UMMZ 219043, 219851, 223881.

Centropodidae: Centropus bengalensis Stephens, 1826 USNM 432050, 613011, 557173, 557172, 343994, 343242, 562047, 562048, 488912, UMMZ 143041; Centropus celebensis Quoy e Gaimard, 1830 USNM 226188, 226189; Centropus cupreicaudus Reichenow, 1896 USNM 488865, 488866; Centropus goliath Bonaparte, 1850 USNM 557151, 557150, 557152, 557171, 557161, 557164, 557157, 557159, 557158, 557165, 557168, 557171; Centropus leucogaster (Leach, 1814) USNM 318594, 292400; Centropus menbeki Garnot, 1828 USNM 489027, 7408; Centropus phasianinus (Vieillot, 1829) USNM 347652, 612694, 612692, 612693, 614952, 612695, MVZ 142200, 142202, UMMZ 224761; Centropus senegalensis Illiger, 1811 USNM 322608, 322607, 322606, 347407, 347409, 347408, UMMZ 205896, 207709, 220213, 235228, 235229; Centropus sinensis Blyth, 1843 USNM 613053, 562050, 562052, 562049, 320078, 343241, 346829; Centropus superciliosus Hemprich e Ehrenberg, 1833 USNM 488163, 431673, 431814, 430785, 19112, 18950, UMMZ 158084, 208304, 208305; Centropus toulou Temminick, 1838 USNM 432196, 208402; Centropus viridis Blyth, 1842 USNM 292310, 561977, 560670, 560669, 611762, 611761, 613054, 613055, 613056, 611763, UMMZ 228025, 228026, 228027.

Neomorphidae: Geococcyx californianus MHNT 110, MVZ 176050, MVZ 7588, UMMZ 116179, 201069, 227058, 227059, 234551, 234552, 236211, 73880, 73881, 85031, USNM 1461, 17486, 346493, 499279, 501304, 554946, 554948, 610961, 610962, 614371; Geococcyx velox Gray, 1847 AMNH 2167, MVZ 85646, 85647, UMMZ 152883, 156461, 156462, 159112; Morococcyx erythropygus Lesson, 1842 AMNH 4604, MVZ 156635, 85641, UMMZ 130940, 133738, 159111, 209205; Neomorphus geoffroyi Gloger, 1827 UMMZ 200592, USNM 431345, 432636.

Crotophagidae: Crotophaga ani LV 13, 14, USNM 492293, 345887, 292576, 289627, USNM 500569, USNM 500420, 555531, 428803, 558088, 553374, MPEG 413, 800, 802, MHNT 221, 237, UMMZ 156539, 218942, 218371, 153436, 218941, 218372, 74684, 219190, 118151, 218940, USNM 559341; Crotophaga major USNM 559340, 430932, 500421, 346328, MHNT 412, 302, MPEG 1337, UMMZ 139989, 152620, 139988, 219191, 218373, 219553; Crotophaga sulcirostris USNM 288787, 288790, 288792, 288793, 288797, 288795, 19161, 491703, 554344, 61467, 612298, MHNT 558, MVZ 120729, 160243, UMMZ 85330, 19559, 133734, 219558, 219556, 219561, 219188, 130939, 151873, 209031, 133735, 133737, 219189, 219555, 219560; Guira guira USNM $428557,614642,614643,614644,614645,227694,322334,345884,345885,321517,499084$, MPEG 725, 1390, 1495, MHNT 333, 111, UMMZ 202013, 202015, 202014, 157046, UMMZ 200661.

Taperidae: Dromococcyx pavoninus Pelzeln, 18703 UMMZ 209207; Dromococcyx phasianellus Wied, 1832 MVZ 85638; Tapera naevia (Linnaeus, 1766) MHNT 1036, MVZ 141740, 94088, UMMZ 135167, 209208, 214004, 214005, 218370, 218946, 222217, USNM $19221,321520,346329$.

Phaenicophaeidae: Ceuthmochares aereus Cabanis e Heine, 1863 UMMZ 158185, 158186, USNM 292401, 292402, 347410, 347411, 347412, 347413; Dasylophus superciliosus Swainson, 1837 UMMZ 228022, 228023, 228024, 228068, USNM 613045, 613046, 613047, 613048, 613049, 613050; Lepidogrammus cumingi Bonaparte, 1854 UMMZ: 233062, 233063, USNM 613051, 613052; Phaenicophaeus pyrrhocephalus Vieillot, 1816 USNM 289689; Rhamphococcyx calyorhynchus Cabanis e Heine, 1862 USNM 226190; Rhamphococcyx curvirostris Cabanis e Heine, 1862 UMMZ 236028, USNM 292224, 559826, 562043, 562044, 562045, 562046; Rhinortha chlorophaea Vigors, 1830 FMNH 106422; Rhopodytes tristis Cabanis e Heine, 1862 USNM 19484, 344002, 344368, 431312; Zanclostomus javanicus Swaison, 1837 UMMZ 236439.

Saurotheridae: Coccycua (Piaya) minuta (Gray, 1846) MHNT 763, UMMZ 139990, 139991, 139992, USNM 32599, 345881, 345882, USNM 345883; Hyetornis pluvialis Sclater, 1862 USNM 558866, 558867, 559182, 559183; Hyetornis rufigularis (Hartlaub, 1852) USNM 226540, 226541, 554608; Piaya cayana Lesson, 1831 MHNT 112, 395, 1140, MPEG 1116, 1163, 1483, UMMZ 133732, 133733, 153092, 158644, 159110, 222215, 222216, 99235, USNM 288783, 289792, 344101, 345878, 347111, 492313, 558792, 559337, 559338, 613974; Piaya melanogaster Schlegel, 1864 UMMZ 209478, USNM 559339; Saurothera merlini d'Orbigny, 1839 UMMZ 158527, USNM 19645, 427940, 429287, 429288, 553324, 555173; Saurothera vetula Vieillot, 1816 USNM 501704, 292567, 292568, 292570, 501735, 501792, 501870, 501920, 554610, 554671, 555760, 555763.

Cuculidae: Cacomantis flabelliformis Bonaparte, 1850 MVZ 143436, UMMZ 214228, USNM 214227, 612636, 612691, 620223; Cacomantis merulinus S. Müller, 1842 USNM 210982, 344369, 488937, 612092; Cacomantis variolosus (Vigors e Horsfield, 1827) USNM 553361, 557147, 557148, 557148, 558292, 558319, 562857; Chalcites basalis Bonaparte, 1854 MVZ 149022, 143438, UMMZ 214232,

Revista Brasileira de Zoologia 23 (3): 608-629, setembro, 2006 
USNM 321459; Chalcites lucidus Lesson, 1831 UMMZ 231601, 213969, 220841, 220896, USNM 554707, 612696, 620222; Chrysococcyx caprius (Boddaert, 1783) UMMZ 212919, 217503, 219889, USNM 322534, 322534, 430685, 431517, 491968, 491969, 491970; Chrysococcyx cupreus Boie, 1827 UMMZ 209197, 218545, USNM 292403, 292404, 318595, 322564,488845; Chrysococcyx klaas (Stephens, 1815) UMMZ 209198, 158083, USNM 322535; Clamator coromandus (Linnaeus, 1766) USNM 343239, 343240, 343522, 343999; Clamator glandarius (Linnaeus, 1758) MVZ 158710, 158713, UMMZ 212907, 212909, 212910, 212911, 212912, 212913, 212914, 212975, 217498, USNM 322440, 430853, 489460, 552918, 552919, 552920, 552931, 552932; Coccyzus americanus Vieillot, 1816 MHNT 455, MHNT 608, UMMZ 154465, 157809, 200573, 201937, 203320, 204022, 205092, 221478, 222084, 73876, USNM 17685, 17694, 19288, 289834, 501300, 501301, 553294, 554343, 557820, 614143; Coccyzus cinereus Vieillot, 1817 USNM 614640, 614641; Coccyzus erythrophthalmus Bonaparte, 1824 MHNT 562, 107156, UMMZ 156020, 156429, 200574, 205253, 205385, 224510, 236040, 236252, 99592, USNM 224424, 224427, 288240, 288241, 288242, 345450, 346327, 377, 499620, 6560; Coccyzus melacoryphus Vieillot, 1817 MHNT 1410, 251, UMMZ 208493, USNM 227775, 612039; Coccyzus minor Gray, 1846 MHNT 547, UMMZ 152623, 208492, 228343, 228344 553323, USNM 555000, 555001, 555535, 555756, 555758, 555759, 557692, 558083, 558085; Cuculus canorus Linnaeus, 1766 UMMZ 119430, 151115, 207051, 235280, USNM 289461, 319219, 319224, 430854, 490318, 490321, 490322, 552921, 552928, 621210; Cuculus clamosus Latham, 1801 UMMZ 212917, 212918, 217502, USNM 431711, 431710, 431831; Cuculus gularis Stephens, 1815 UMMZ 217501; Cuculus pallidus Schlegel, 1864 MVZ 143437, UMMZ 206513, 214226, 214240, 206513; Cuculus poliocephalus Latham, 1790 UMMZ 234936, USNM 559099; Cuculus saturatus Blyth, 1843 UMMZ 207450, USNM 292061, 292063, 560668, 289904; Cuculus solitarius Stephens, 1815 MVZ 133800, UMMZ 212916; Cuculus sparverioides Vigors, 1832 USNM 343990, 343991, UMMZ 233058; Cuculus variolosus (Vigors e Horsfield, 1827) UMMZ 207451, 228020, 228021, 233059, 233060; Eudynamys scolopacea (Linnaeus, 1758) UMMZ 210347, USNM 226186, 290380, 292053, 292056, 292059, 292060, 318239, 319914, 345034, 490192; Misocalius osculans (Cabanis e Heine, 1862) UMMZ 214229, UMMZ 214230; Oxylophus jacobinus Cassin, 1856 MVZ 158714, 158715, USNM 430440, 431797, 489458, 489467, 489470, UMMZ 212889, 212893, 212894, 212895, 212896, 212897, 212898, 212900, 212901, 212904; Oxylophus levaillantii (Swainson, 1829) FMNH 319965, UMMZ 158583, 212906, 217499, USNM 347406; Penthoceryx sonneratii (Latham, 1790) UMMZ 223664; Surnicullus lugubris (Lesson, 1831) USNM 488329, 562053, 562176; Surnicullus velutinus Sharpe, 1877 UMMZ 233061; Urodynamis taitensis Salvadori, 1880 USNM 554705, 559589.

\section{Grupos externos}

Musophagidae: Corythaeola cristata (Vieillot, 1816) USNM 291080, 291079; Corythaixoides concolor (A. Smith, 1833) USNM 430382, 558533, 558534, 558535; Corythaixoides leucogaster (Rüppell, 1842) USNM 430813, 431676, AMNH 1983, 1985, 10538, 3720, 1985; Corythaixoides personata (Rüppell, 1842) USNM 318500, MHNT 1517; Crinifer piscator (Boddaert, 1783) USNM 322457, 322460, 322458, UMMZ 152882; Crinifer zonorus (Rüppell, 1870) USNM 430522, UMMZ 219046; Musophaga rossae Gould, 1851 USNM 558255, AMNH 10539, 5006, UMMZ 222605; Musophaga violacea Isert, 1788 AMNH 456, MNHT 1516; Ruwenzorornis johnstoni (Sharpe, 1901) AMNH 8943; Tauraco corythaix (Wagler, 1827) USNM 489402, 555600, 18998, 613749, 621039, UMMZ 215883; Tauraco erythrolophus (Vieillot, 1819) AMNH 8209, 12666, USNM 500302, MHNT 891, UMMZ 215881; Tauraco hartlaubi (Fischer \& Reichenow, 1884) USNM 431674, 431675, 431800, 429846, AMNH 10890, 10979, MHNT 1513, UMMZ 234273, 222604, 222603, 152364, 208303, 208302; Tauraco leucolophus (Heuglin, 1855) AMNH 4156; Tauraco leucotis (Ruppell, 1835) USNM 488060, 319973, 290149, 289729, 430176, 321846, MNHT 538; Tauraco livingstoni (Gray, 1864) USNM 491348, 559413, UMMZ 158184; Tauraco macrorhynchus (Fraser, 1839) USNM 291082, 291083; Tauraco persa (Linnaeus, 1758) USNM 428082, 291319, 291081, 346950, 431973; Tauraco porphyreolophus (Vigors, 1831) USNM 499380, 490282, 490278, AMNH 2162, 4734, UMMZ 158183, 214360.

Anseriformes

Anhimidae: Chauna torquata (Oken, 1816) MHNT 389.

Anatidae: Dendrocygna bicolor (Vieillot, 1816) MHNT 344; Anseranas semipalmata (Latham, 1798) MHNT 1696.

Galliformes

Cracidae: Crax alector Linnaeus, 1766 MPEG 2178; Crax fasciolata (Spix, 1825) MPEG 1512, 1513, 1955, 275, 457, 607, 689; Crax globulosa Spix, 1825 MPEG 1147, 1302, 355, 424, 435, 606, 690, 928; Mitu tuberosa (Spix, 1825) MPEG 354, 641, 645, 646, 656, 683; Nothocrax urumutum (Spix, 1825) MPEG 329, MPEG 794; Ortalis motmot (Linnaeus, 1766) MPEG 249, 374, 699, 701; Ortalis superciliaris Gray, 1867 MPEG 543, 624; Penelope pileata Wagler, 1830 MPEG 1590, 718, 912, 923; Penelope superciliaris Temminck, 1815 MPEG 1931 569, 707, 709, 710, 711, 712; Pipile cujubi (Pelzeln, 1858) MPEG 1323, 1557, 666, 755; Pipile cumanensis (Jacquin, 1784) MPEG 591. 
Apêndice 2. Lista de modificações dos caracteres comportamentais de HuGHEs (1996) utilizados na análise cladística.

Caráter 1 ("generalized habit use"): Para Crotophaga e Guira, ao invés de considerá-los como arborícolas, foram considerados como uma condição intermediária entre os hábitos arborícola e terrícola (caráter 231) pois, embora nidifiquem em árvores, forrageiam basicamente no solo (Davis 1940a,b, 1942, Macedo 1992, Souza 1995, Martins \& Donatell 2001).

Caráter 3 ("primary diet"): inverteu-se a polaridade da condições 1 e 3, ou seja, a condição 1 passa ser a 3 e vice-versa (caráter 233). Foram considerados assim de acordo com a polaridade encontrada no cladograma geral para a osteologia. Além disso, o item alimentar é de difícil polarização pois não são observadas séries claras de transformações, sendo necessário uma hipótese de polaridade previamente estabelecida.

Caráter 6 ("degree of social interaction during breeding season"): Foi subdividido em dois caracteres binários (caracteres 236 e 237 ) em virtude de Hughes ter polarizado com base também em Opisthocomus que apresenta condição distinta de Musophagidae. Assim, o primeiro binário (caráter 236) refere-se à condição de se reunir em pequenos bandos durante a época reprodutiva, considerada como plesiomorfia (encontrada em Musophagidae), e solitária (sinapomorfia para os cucos em geral). Já o segundo caráter binário (caráter 237) se refere à condição de se reunir em ninhos gregários durante tal época (sinapomorfia para Guira e Crotophaga).

Caráter 7 ("territoriality during breeding season"): Foi excluída a condição não-territorial (condição 3 como "não-comparável": caráter 238) apresentada somente por Pachycoccyx (autapomorfia para o gênero) por entender-se que a condição do território defendido por macho e/ou fêmea não é comparável com a daquela ave que não defende seu território.

Caráter 19 ("sex incubating eggs"): foi retirada a condição 3 por se tratar de cucos que não incubam ovos (parasitas de ninhos), portanto considerados não comparáveis com os demais. Ainda, as condições 1 e 2 foram divididas binariamente em dois caracteres distintos (caracteres 248 e 249) pois podem não se tratar de caracteres multiestados com série de transformações (incubação feita pelo macho ou pela fêmea).

Apêndice 3. Lista dos caracteres da osteologia craniana e respectivos passos mínimos (n) e o índice de consistência (ic). Quando não há o " $n$ " e "ic" no caráter, significa $n=1$ e ic $=1$ e quando se apresenta um segundo número (caracteres 15, 52 e 143), significa o mínimo e o máximo de " $\mathrm{n}$ " ou "ic" para os caracteres ambíguos nas 18 árvores igualmente parcimoniosas.

Ossa cranii

1. Sutura lacrimofrontal: (0) longa, (1) curta); 2. Sutura nasofrontal: (0) fundida medialmente, (1) fundida medialmente; 3 . Depressão rostral do frontal: ( 0 ) rasa ou ausente, (1) profunda $(n=3$, ic $=0,33$; 4 . Depressão rostral profunda do frontal: $(0)$ presente, $(1)$ mais reduzida e mais rasa; 5 . Depressão (Concavidade) rostromedial no osso frontal: (0) presente, $(1)$ ausente $(n=8$, ic $=0,167)$; 6 . Proeminência medial na porção dorsorostral do osso frontal: (0) ausente, $(1)$ presente $(n=3$, ic $=0,33) ; 7$. Processo lacrimal do frontal: (0) reduzido, (1) largo, (2) idem 1, mas mais largo $(n=7$, ic = 0,286); 8. Largura lateral do frontal: (0) ampla (62 a $73 \%$ da largura lateral do teto parietal), (1) ampla, mas mais estreita do que 0 (52 a 58\%) (2) mais estreita (40 a 48\%) (3) idem 2, mas ainda mais estreita (21 a 38\%) $(n=14$, ic $=0,214)$; 9 . Concavidade medial do margo supraorbitalis: $(0)$ ausente, (1) presente $(n=2$, ic $=$ $0,5)$; 10. Fossa lateral do frontal $(0)$ ausente, $(1)$ presente $(n=2, i c=0,5) ; 11$. Fossa lateral do frontal: (0) posicionada mais ventralmente no crânio (mais próxima do processo pós-orbital), (1) posicionado mais dorsalmente no crânio e ampla (larga) (2) idem 1, mas estreita (3) idem 2, mas ainda mais estreita $(n=5$, ic $=0,5) ; 12$. Fossa lateral do frontal: (0) dorsal, profunda e estreita, (1) idem 0 , mas é mais estreita e mais rasa $(n=2$, ic $=0,5)$; 13 . Proeminência na porção dorsal frontoparietal (calvaria): (0) larga e proeminente, (1) larga e baixa (não proeminente), (2) estreita e reduzida $(n=5$, ic $=0,4) ; 14$. Proeminência cerebelar: (0) proeminente, (1) reduzida (não proeminente) $(n=7$, ic $=0,143)$; 15 . Processo paraoccipital com expansão rostral e depressão lateral: (0) ausente, (1) presente ( $\mathrm{n}=1$ ou 2 , ic $=1$ ou 0,5$) ; 16$. Posição do óstio do canal da carótida: (0) na linha da crista basilar ou caudal à crista basilar, (1) rostral à crista basilar $(n=4$, ic $=0,25) ; 17$. Fossa subcondilar: $(0)$ profunda, $(1)$ rasa $(n=3$, ic $=0,33)$; 18 . Fossa subcondilar: (0) ampla, (1) reduzida; 19. Tubérculo basilar: (0) vestigial ou ausente, (1) proeminente $(n=4$, ic $=0,25) ; 20$. Hiatus subtympanicus (Hughes 2000): (0) estreito, ( 1 largo $(n=2$, ic = 0,5); 21. Projeção paraesfenóide: (0) distante do rostro paraesfenoidal, (1) próxima ao rostro paraesfenoidal; 22. Projeção paraesfenóide: (0) a porção distal rostral é triangular, (1) a porção distal é mais estreita e mais longa ( $n=3$, ic =0,333); 23. Lâmina paraesfenóide: (0) saliente (proeminente), (1) achatada (não proeminente); 24. Depressão medial da lâmina paraesfenóide: (0) rasa ou ausente, (1) profunda $(n=2$, ic $=0,5) ; 25$. Processo lateral paraesfenóide: (0) reduzido e estreito (não recobre a cavidade timpânica ventralmente), (1) amplo (recobre a porção medioventral da cavidade timpânica), (2) idem 1, mas mais ampla (recobre metade da cavidade timpânica) $(n=5$, ic $=0,4)$; 26 . Processo lateral paraesfenóide vestigial (forma de um tubérculo): (0) ausente, (1) presente; 27. Processo lateral paraesfenóide: (0) reduzido e não projetado ventralmente (curto), (1) mais estreito e longo (projetando-se ventralmente); 28. Porção caudal do processo lateral do paraesfenóide: (0) estreita (em forma de barra), (1) larga, arredondada e achatada $(n=3$, ic $=0,33) ; 29$. Fossa lateral do paraesfenóide: (0) ausente, (1) presente $(n=3$, ic $=0,33)$, 30. Processo basipterigóide: (0) posicionado caudalmente, (1) posicionado rostralmente ou vestigial, (2)

Revista Brasileira de Zoologia 23 (3): 608-629, setembro, 2006 
idem 1, mas mais proeminente lateralmente, (3) idem 2, mas mais largo rostrocaudalmente $(n=3$, ic $=1)$; 31 . Ectetmóide: $(0)$ vestigial, (1) largo lateralmente (atinge metade da distância entre sua inserção no septo nasal e barra jugal), (2) mais largo lateralmente (atinge mais da metade da distância acima) e é mais espesso, (3) idem 2, mas é mais delgado que 2, (4) idem, 3 mas é ainda mais delgado (n $=13$, ic $=0,308$ ), 32. Projeção lateral do ectetmóide (porção dorsal): (0) ausente ou vestigial (como um pequeno tubérculo distante do processo supra-orbital do lacrimal), (1) estreita (ainda distante do proc. supra-orbital do lacrimal), (2) larga (mais próximo do processo supra-orbital do lacrimal), (3) idem 2, mas mais larga (mais próximo ou em contato com o processo supra-orbital do lacrimal) $(n=3$, ic $=1$ ); 33. Projeção lateral do ectetmóide (projeção dorsal) mais próximo ou em contato com o processo supra-orbital do lacrimal: (0) próximo, mas não em contato com o processo supra-orbital, (1) lateralmente mais largo (contatando-se com a margem medial do processo supra-orbital do lacrimal), (2) ainda lateralmente mais largo (contatando-se com a margem lateral do processo supra-orbital do lacrimal) $(n=4$, ic $=0,5)$; 34. Projeção lateral do ectetmóide (porção ventral): (0) lateralmente larga e dorsoventralmente estreita, (1) lateralmente estreita (distante da barra jugal) e dorsoventralmente larga, (2) idem 1, mas lateralmente mais larga (metade da distância entre sua inserção no septo interorbital e a barra jugal) (3) idem 2, mas lateralmente mais larga (mais próximo ou em contato com a barra jugal) $(n=6, i c=0,5) ; 35$. Porção distal da porção ventral do ectetmóide: $(0)$ arredondada, (1) pontiaguda $(n=3$, ic $=$ 0,33); 36. Crista na superfície rostral do ectetmóide: (0) ausente, (1) presente; 37. Crista na superfície rostral do ectetmóide: (0) proeminente e larga, (1) proeminente, (2) vestigial ou ausente $(n=2$, ic $=1)$; 38. Sutura nasolacrimal: $(0)$ curta, $(1)$ longa $(n=3$, ic = 0,33); 39. Processo supra-orbital do lacrimal: (0) retangular e longo, (1) arredondado, reduzido (mais estreito) e a margem lateral é reta, (2) idem 1, mas a margem lateral é mais larga, (3) idem 2, mas é ainda mais largo lateralmente $(n=9$, ic $=0,33)$; 40. Processo supra-orbital do lacrimal mais curto e arredondado: (0) margem lateral é reta, (1) margem lateral é pontiaguda (triangular) $(n=2$, ic $=$ 0,5); 41. Posição do processo supra-orbital no crânio: (0) inclinado, (1) perpendicular; 42. Processo supra-orbital do lacrimal: (0) delgado, (1) espesso; 43. Projeção lateral na porção ventral do processo supra-orbital: (0) ausente, (1) presente $(n=2$, ic $=0,5)$, 44 . Processo orbital do lacrimal: (0) longo (próximo a barra jugal) e inclinado, (1) curto e mais perpendicular, (2) mais perpendicular, mas é mais longo (próximo à barra jugal $(n=2$, ic $=0,5)$; 45. Processo orbital mais longo e perpendicular ao crânio: (0) longo e largo, apresentando um curvatura medial, (1) mais largo lateralmente, (2) estreito $(n=2$, ic $=1)$; 46. Processo orbital do lacrimal: (0) longo ou curto, (1) reduzido (tubercular) $(n=4$, ic $=0,25)$; 47. Processo orbital do lacrimal: (0) curto ou longo, estreito ou largo, (1) mais longo e largo (próximo à barra jugal), (1) ainda mais longo e mais largo (contatando-se com a barra jugal) e perpendicular à caixa craniana, (2) Ainda mais longo e largo (ultrapassando a linha ventral da barra jugal) e perpendicular à caixa craniana $(n=7$, ic $=0,429)$; 48. Processo orbital do lacrimal curto, dorsalmente largo e ventralmente espicular: (0) ausente, (1) presente; 49. Processo orbital lateralmente achatado: (0) ausente, (1) presente; 50. Depressão na superfície lateral do processo orbital: (0) ausente, (1) presente; 51. Protuberância caudolateral do lacrimal: (0) ausente, (1) presente $(n=2$, ic $=0,5)$; 52 . Tubérculo mediorostral do lacrimal: (0) ausente, (1) presente ( $\mathrm{n}=9$ ou 10 , ic $=0,111$ ou 0,1$) ; 53$. Posição do canal do nervo facial (Huches 2000): (0) no mesmo nível ou rostrocaudal ao meatus acusticus externus, (1) caudal ao meatus acusticus externus: 54. Forma da região ótica definida pela ala timpânica e proc. oticus do quadrado em aspecto lateral (Huches 2000): (0) curta e oval, (1) longa e oval ( $n=2$, ic $=0,5) ; 55$. Região ótica como acima, ângulo da corda mais longa (HuGHes 2000): (0) 15 a 45, (1) 45 a 90 $(n=4$, ic $=0,25)$; 56. Processo zigomático: (0) reduzido e tubercular (16 a $36 \%$ da distância entre sua inserção no crânio e a barra jugal), (1) curto, mas mais longo que 0 (39 a $47 \%$ da distância acima), (2) longo (50 a 68\%) $(n=9$, ic $=0,22)$; 57. Processo zigomático tubercular: (0) estreito, (1) lateralmente mais largo $(n=2$, ic $=0,5) ; 58$. Processo suprameático: (0) longo e largo, (1) curto e largo, (2) idem 1, mas mais estreito e pontiagudo $(n=3$, ic $=0,667) ; 59$. Tubérculo na superfície ventrolateral da fossa subtemporal: $(0)$ presente, $(1)$ ausente $(n=2$, ic $=0,5) ; 60$. Crista transversa na fossa temporal: $(0)$ ausente, (1) presente; 61. Crista transversa da fossa temporal: (0) longa dorsoventralmente (em contato com a crista temporal dorsal), (1) curta dorsoventralmente (não há contato com a crista temporal dorsal); 62. Crista transversa da fossa temporal: (0) presente e mais longa (separando a crista temporal em duas porções), (1) presente e mais curta ( $n=2$, ic $=0,5) ; 63$. Fossa temporal rostral: (0) ausente ou estreita, (1) larga; 64. Fossa temporal: (0) reduzida (confinada a porção rostral do crânio), (1) larga, mas rasa e estreita (restrita à porção lateral do crânio), (2) idem 1, mas mais larga (profunda e caudalmente ampla, alcançando a porção caudal do crânio), (3) idem 2, mas mais profunda e mais larga (as duas fossas temporais estão mais próximas na porção caudal do crânio) $(n=8$, ic $=0,375) ; 65$. Fossa temporal estreita (restrita à porção lateral do crânio): (0) rasa, (1) profunda $(n=2, i c=0,5), 66$. Fossa subtemporal: (0) ausente, (1) presente; 67. Fossa subtemporal: (0) ampla e rasa, (1) estreita e rasa, (2) mais estreita e profunda $(n=11$, ic $=0,182) ; 68$. Porção caudal da fossa subtemporal: (0) ampla e caudalmente arredondada, (1) estreita e caudalmente pontiaguda; 69. Processo pós-orbital: (0) reduzido (tubercular) e ventralmente posicionado, (1) dorsalmente posicionado; 70. Processo pós-orbital posicionado dorsalmente: (0) proeminente (longo: 24 a 40\% da distância de inserção basal à barra jugal), (1) curto (16 a 20\% desta mesma distância), (2) reduzido (12 a 13\%), (3) tubercular e mais reduzido (5 a 8\%) $(n=10$, ic $=0,3)$; 71. Processo pós -orbital longo, largo em sua porção dorsal e pontiagudo na porção ventral: $(0)$ ausente, $(1)$ presente $(n=2$, ic $=0,5)$.

Orbita

72. Fossa na porção caudal da órbita: (0) rasa e ampla, (1) profunda e ampla, (2) profunda e estreita, (3) rasa mais estreita $(\mathrm{n}=7$, ic $=$ 0,429), 73. Fossa na porção caudal do órbita: (0) ampla (ocupando no máximo de 40 a $50 \%$ da parede caudal da órbita), (1) mais 
ampla (ocupando mais de $50 \%$ da parede caudal da órbita) e mais profunda; 74 . Fontículo orbitocranial: (0) reduzido (pequena abertura confinada à porção dorsocaudal do septo interorbital) ou ausente, (1) longo (estendendo-se à porção rostral do septo interorbital) e largo dorsoventralmente $(n=5$, ic $=0,2)$, 75. Fontículo interorbital reduzido, mas não distinto do forâmen óptico: (0) ausente, (1) presente; 76. Fontículo interorbital: (0) reduzido (do calibre de um forâmen) ou ausente, (1) reduzido (pequena abertura que abrange não mais que $20 \%$ do septo interorbital), (2) amplo (abrange cerca de $30 \%$ ou mais do septo interorbital); $(n=8$, ic $=0,25)$, 77. Sulco para o nervo olfatório: (0) profundo, (1) profundo mas ausente em sua porção caudal (curto), (2) raso $(n=3$, ic $=0,667)$; 78. Forâmen orbitonasal medial: (0) reduzido ou ausente, $(1)$ amplo $(n=4$, ic $=0,25)$; 79 . Forâmen orbitonasal lateral: (0) reduzido ou ausente, (1) amplo ( $\mathrm{n}=2$, ic $=0,5)$.

Facies

80. Maxila superior: (0) curta e pontiaguda na porção rostral, (1) longa e estreita, (2) idem 1, mas é mais larga caudalmente e não é proeminente em sua porção dorsocaudal $(n=2$, ic $=1)$; 81 . Maxila superior: $(0)$ curta e pontiaguda na porção rostral, $(1)$ longa e arredondada na porção caudal, (2) idem 1, mais é ainda mais larga e arredondada caudalmente $(n=4$, ic $=0,5)$; 82 . Maxila superior longa, estreita e não proeminente no porção caudal: (0) ausente, (1) presente; 83. Maxila superior curta, larga e não proeminente no porção caudal: (0) ausente, (1) presente (38 a $40 \%$ do comprimento total do crânio) ( $n=4$, ic $=0,250)$; 84 . Maxila superior curta, larga caudalmente e pontiaguda rostralmente e apresentando curvatura ventral mais acentuada em toda a sua extensão: (0) ausente, (1) presente; 85. Curvatura ventral do ápice do pré-maxilar: (0) proeminente, (1) baixa (não proeminente), (2) vestigial ou ausente $(\mathrm{n}=7$, ic $=0,286), 86$. Ápice rostral da maxila superior: (0) largo, (1) estreito, (2) mais estreito (rostralmente pontiagudo) $(\mathrm{n}=3, \mathrm{ic}=$ $0,667), 87$. Depressão medial na porção rostroventral do maxila superior: $(0)$ ausente, $(1)$ presente $(n=2$, ic $=0,5)$; 88 . Depressão mediorostral entre os processos maxilares do palatino: $(0)$ ausente, $(1)$ presente $(n=3$, ic $=0,33)$; 89 . Depressão entre os processos maxilares do palatino: (0) rasa e estreita (restrita à linha mediana da face ventral da maxila superior), (1) profunda; 90 . Fusão medial na superfície ventral da maxila superior: (0) total (o assoalho da maxila superior está totalmente fundido), (1) parcialmente fundida, com abertura medial estreita, (2) idem 1, mas a abertura é mais ampla (lateralmente mais larga e mais longa rostrocaudalmente) ( $n=2$, ic = 1); 91. Fusão entre o processo jugal e o processo maxilar do osso pré-maxilar: (0) ausente (não fundido), (1) fundidos entre si; 92. Processo jugal: (0) largo e curto, (1) largo e longo, (2) estreito e longo, (3) estreito e curto $(n=12$, ic $=0,25)$; 93 . Processo jugal: (0) delgado, (1) espesso $(n=2, i c=0,5)$; 94 . Fusão medial entre os processos maxilopalatinos: (0) não fundidos na porção rostral, (1) fundidos na porção rostral com uma larga abertura na porção medial dos maxilopalatinos, (2) fundidos na porção rostromedial (a abertura é mais estreita), (3) fundidos em toda a extensão $(n=5$, ic $=0,6)$; 95 . Depressão medial entre os processos maxilopalatinos: (0) estreita e rasa, (1) estreita e ainda mais rasa; 96. Depressão medial entre os processos maxilopalatinos: (0) estreito e rasa, (1) estreita e mais profunda $(n=2$, ic $=0,5)$; 97 . Superfície ventral dos processos maxilopalatinos: (0) lateralmente achatada, (1) dorsoventralmente achatada, (2) idem 1, mas mais dorsolateralmente achatada (mais larga lateralmente) $(n=2$, ic $=1)$, 98. Processos maxilopalatinos: (0) largos e espessos, (1) estreitos e delgados, (2) mais estreitos e delgados ( $n=3$, ic $=0,667)$, 99. Porção caudal do septo nasal: (0) curta (1) a porção ventral é mais longa (próxima à porção distal rostral do rostro paraesfenóide), (2) idem 1, mas ainda mais longa (mais próxima ou ultrapassa rostralmente o ápice rostral do rostro paraesfenoidal) $(n=6$, ic $=0,33) ; 100$. Processo maxilar do nasal: (0) estreito (1) largo $(n=3$, ic $=0,33) ; 101$. Processo maxilar do nasal: (0) delgado, (1) espesso em sua porção ventromedial; 102. Porção dorsal do processo maxilar do nasal: (0) estreita, (1) larga lateralmente, (2) ainda mais larga lateralmente (expandindo-se até a margem lateral do processo supra-orbital do lacrimal) $(n=9$, ic $=0,22)$; 103 . Região supranasal (Pila supranasalis): (0) estreita, (1) larga e achatada, (2) idem 1, mas espessa e com uma elevação dorsal, (3) idem 2, mas mais espessa e a elevação dorsal é mais proeminente (n $=4$, ic $=0,75)$; 104. Região supranasal: (0) estreita ou larga, (1) rostralmente estreita e caudalmente larga; 105. Abertura nasal: (0) totalmente aberta, mas do tipo esquizorina, (1) há uma reduzida lâmina cobrindo a porção caudal da narina holorina, (2) idem 1, mas a abertura nasal é mais larga caudalmente: demais Cuculiformes, (3) narina do tipo holorina, mas a lâmina é ausente $(n=7$, ic $=0,429)$; 106. Abertura nasal coberta por uma lâmina óssea: (0) ausente, (1) a lâmina é caudalmente mais larga (há somente uma reduzida abertura rostroventral), (2) a lâmina é mais reduzida caudalmente (a abertura nasal está separada em duas porções através de uma lâmina mediana mais reduzida) $(n=5$, ic $=0,666)$; 107 . Lâmina óssea na narina cobrindo somente a porção rostral da narina: $(0)$ ausente, (1) presente; 108. Lâmina óssea da narina: (0) cobrindo parte da porção rostral da narina, (1) lâmina mais ampla e mais espessa, cobrindo a maior parte da narina (exceto sua porção caudal), (2) lâmina ainda mais ampla, cobrindo a porção dorsocaudal da narina, há somente uma estreita abertura na porção caudal da narina $(n=2, i c=1)$; 109 . Crista na superfície ventral da narina: (0) ausente, (1) presente $(n=4$, ic $=0,25) ; 110$. Crista na superfície ventral da narina: (0) proeminente e longa (estendendo rostrocaudalmente em toda a superfície ventral da narina ou até a metade da extensão da narina), (1) não proeminente e curta caudalmente (não atinge metade da extensão da abertura nasal), (2) reduzida (em forma de um tubérculo, confinado à porção rostral da narina) $(n=2$, ic = 1).

Os palatinum, os vomer, os pterigoideum, os jugale et quadratojugale, os quadratum

111. Palato: (0) aberto (os palatinos não estão fundidos entre si) e os palatinos são mais estreitos lateralmente, (1) parcialmente aberto (somente a porção rostrodorsal da parte caudal dos palatinos estão fundidos entre si) e os palatinos são estreitos, (2) fechado (toda

Revista Brasileira de Zoologia 23 (3): 608-629, setembro, 2006 
a porção dorsocaudal dos palatinos estão fundidos entre si) e os palatinos são largos ( $n=3$, ic $=0,667)$; 112 . Processo maxilar do palatino: (0) largo em toda a sua extensão, (1) estreito em sua porção rostral $(n=2$, ic $=0,5) ; 113$. Processo maxilar do palatino: (0) largo em toda a sua extensão, (1) estreito em sua porção mediana; 114. Porção caudal dos ossos palatinos: (0) não se contatando entre si (há uma larga abertura entre eles), (1) há um reduzido contato entre si na extremidade caudal (a abertura é mais reduzida e mais estreita do que 0$)$, (2) toda a porção caudal está em contato entre si (a abertura é ausente) $(n=3$, ic $=0,667)$; 115. Palatino: (0) estreito em toda a sua extensão, (1) estreito rostralmente mas amplo caudalmente (mais próximo da barra jugal), (2) estreito rostralmente, mas caudalmente é mais estreito do que 1 (mais distante da barra jugal), (3) estreito rostralmente, mas é ainda mais estreito caudalmente (ainda mais distante da barra jugal) $(n=6$, ic $=0,5) ; 116$. Fossa coanal: (0) larga em toda a sua extensão, (1) mais estreita em toda a sua extensão, (2) ainda mais estreita em toda a sua extensão, (3) ainda estreita, porém mais larga na porção medial, (4) idem 3, mas medialmente ainda mais larga $(n=12$, ic $=0,333)$; 117 . Crista ventral do palatino: (0) não proeminente (inconspícua ou ausente), (1) menos proeminente (conspícua, reduzida), (2) ainda mais proeminente (como uma parede na parte medial da porção caudal do osso palatino) $(n=5$, ic $=0,4)$, 118. Processo rostral da crista ventral do palatino: (0) ausente, (1) presente; 119. Processo rostral da crista ventral do palatino: (0) curto, porém sua porção rostral distal é pontiaguda: Cuculiformes, (1) longo, com porção distal pontiaguda, (2) curto (tubercular) $(n=6$, ic $=0,333)$; 120. Lamela coanal: (0) presente, (1) ausente; 121. Lamela coanal: (0) proeminente e estreita, (1) menos proeminente e larga; 122. Lamela coanal: (0) proeminente e estreita, (1) reduzida (somente com uma discreta elevação confinada à porção rostral da parte caudal do palatino, próximo lateralmente à porção rostral do rostro paraesfenoidal $(\mathrm{n}=3$, ic $=0,33)$; 123. Vômer: (0) longo, largo e laminar (achatado lateralmente), (1) reduzido e estreito, (2) vestigial ou ausente; $(n=2$, ic $=1)$; 124 . Crista dorsal do pterigóide: (0) ausente, (1) presente $(n=2$, ic $=0,5)$, 125. Crista dorsal do pterigóide: (0) presente mas menos proeminente (reduzida), (1) proeminente, (2) mais proeminente (apresenta a mesma largura do pterigóide) $(n=10$, ic $=0,2) ; 126$. Expansão rostral do pterigóide: (0) presente e proeminente, (1) vestigial (praticamente ausente); 127. Arco jugal: (0) fundido com o processo maxilar do osso nasal, (1) fundido com o processo jugal do osso pré-maxilar; 128. Expansão lateral na porção rostral da barra jugal: (0) ausente, (1) presente; 129. Expansão lateral na porção rostral da barra jugal: (0) presente e estreita, (1) larga; 130. Processo orbital do osso quadrado: (0) longo, (1) curto, (2) mais curto e mais largo $(n=7, i c=0,286) ; 131$. Tamanho dos côndilos lateral e medial do quadrado: $(0)$ lateral $>$ medial, $(1)$ lateral $=m e d i a l(n=3$, ic $=0,333)$.

Ossa mandibulae

132. Maior largura (abertura) entre os ramos mandibulares: (0) largo (mais do que $60 \%$ do total comprimento do mandíbula), (1) estreito (46 a 59\% desta medida), (2) ainda mais estreito (34 a 43\%) $(n=8$, ic $=0,25)$; 133 . Porção sinfisial da mandíbula: (0) reduzida (8 a 12\% do comprimento total da mandíbula), (1) curta (15 a 18\% deste comprimento), (2) longa (20 a 25\%), (3) mais longa (27 a 35\%) $(n=11$, ic $=0,273) ; 134$. Parte sinfisial da mandíbula: (0) estreita lateralmente, (1) larga lateralmente e espessa; 135. Ramo mandibular: (0) largo dorsoventralmente, (1) estreito dorsoventralmente $(n=2$, ic $=0,5)$; 136 . Ramo mandibular: ( 0$)$ delgado, (1) espesso ( $n=3$, ic $=0,33)$; 137. Expansão lateral do ramo mandibular: (0) ausente ou reduzida, (1) presente $(n=2$, ic =0,5); 138. Osso dentário: (0) não fundido com os outros ossos da mandíbula, (1) completamente fundido com os outros ossos da mandíbula; 139. Fossa rostral na superfície medial do ramo mandibular: (0) curta (confinada à porção rostral da mandíbula), (1) longa (estendendo-se à porção caudal da mandíbula), ampla (estendendo-se por praticamente toda a superfície dorsoventral da face medial da mandíbula) e profunda, (2) longa, ampla e rasa, (3) longa, estreita (não se expandindo por toda a superfície dorsoventral) e rasa $(n=9$, ic $=0,333) ; 140$. Lâmina óssea: (0) cobrindo todo o fontículo caudal da mandíbula, (1) cobrindo parcialmente o fontículo caudal, restando somente uma reduzida abertura $(n=5, i c=0,2) ; 141$. Número de processos coronóides: $(0)$ somente um, (1) dois $(n=2$, ic $=0,5)$; 142. Tamanho relativo dos processos coronóides 1 e 2: (0) $1>2$, (1) $1=2(n=3$, ic $=0,3)$; 143. Tubérculo pseudotemporal: (0) ausente ou vestigial, (1) proeminente $(n=5$ ou 6 , ic $=0,2$ ou 0,167$) ; 144$. Profundidade relativa das cótilas medial e lateral da mandíbula: (0) a mesma profundidade, (1) a cótila medial é mais profunda do que a cótila lateral; 145 . Processo medial da mandíbula: (0) longo e estreito, (1) curto e largo. (2) idem 1, mas mais estreito na porção distal $(n=2$, ic $=1)$; 146 . Forâmen pneumático: (0) amplo, (1) reduzido; 147. Tubérculo laterocaudal do processo medial da mandíbula: (0) ausente, (1) presente $(n=3$, ic $=0,33) ; 148$. Tubérculo medial do processo medial da mandíbula: (0) proeminente e largo, (1) reduzido (vestigial) e estreito ( $n=3$, ic $=0,33) ; 149$. Processo retroarticular: (0) longo e estreito, (1) reduzido (tubercular); 150 . Depressão na superfície lateral na porção caudal da mandíbula: $(0)$ ausente, $(1)$ presente $(n=2, i c=0,5) ; 151$. Depressão na superfície lateral na porção caudal da mandíbula: (0) ampla, (1) estreita $(n=3$, ic $=0,333)$; 152. Fossa caudal da mandíbula: (0) mais ampla, (1) ampla, (2) estreita ( $\mathrm{n}=9$, ic $=0,222)$.

Apparatus hyobranchialis

153. Forma do os basibranchiale rostrale em aspecto lateral (Hughes 2000): (0) margo ventralis reto, (1) protusão proeminente próxima à linha mediana do margo ventralis; 154 . Largura relativa das extremidades distal e proximal do os basibranchiale em aspecto lateral (Hughes 2000): (0) larguras semelhantes, (1) extremidade distal mais larga que a proximal $(\mathrm{n}=2$, ic $=0,5$ ).

Revista Brasileira de Zoologia 23 (3): 608-629, setembro, 2006 


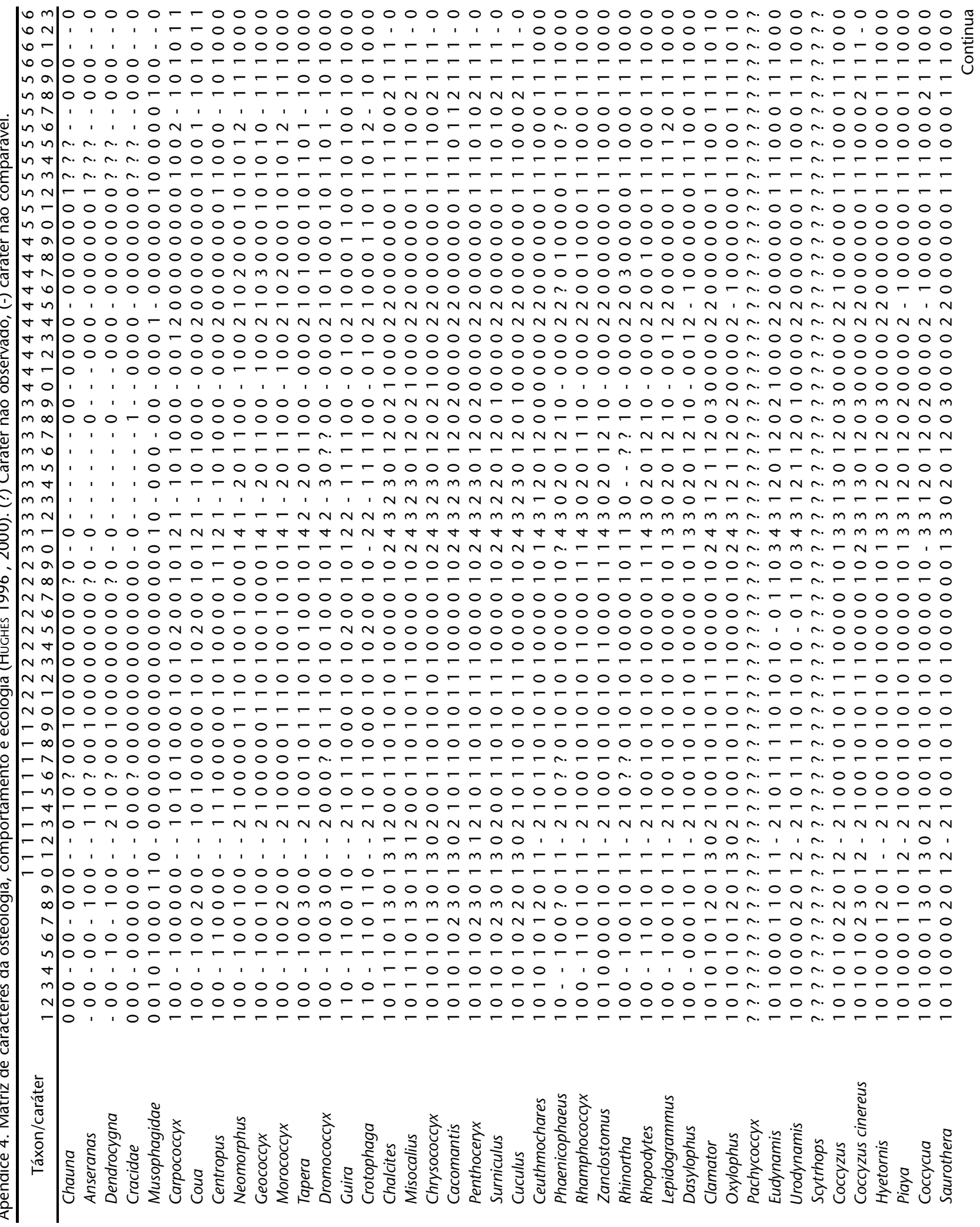

Revista Brasileira de Zoologia 23 (3): 608-629, setembro, 2006 


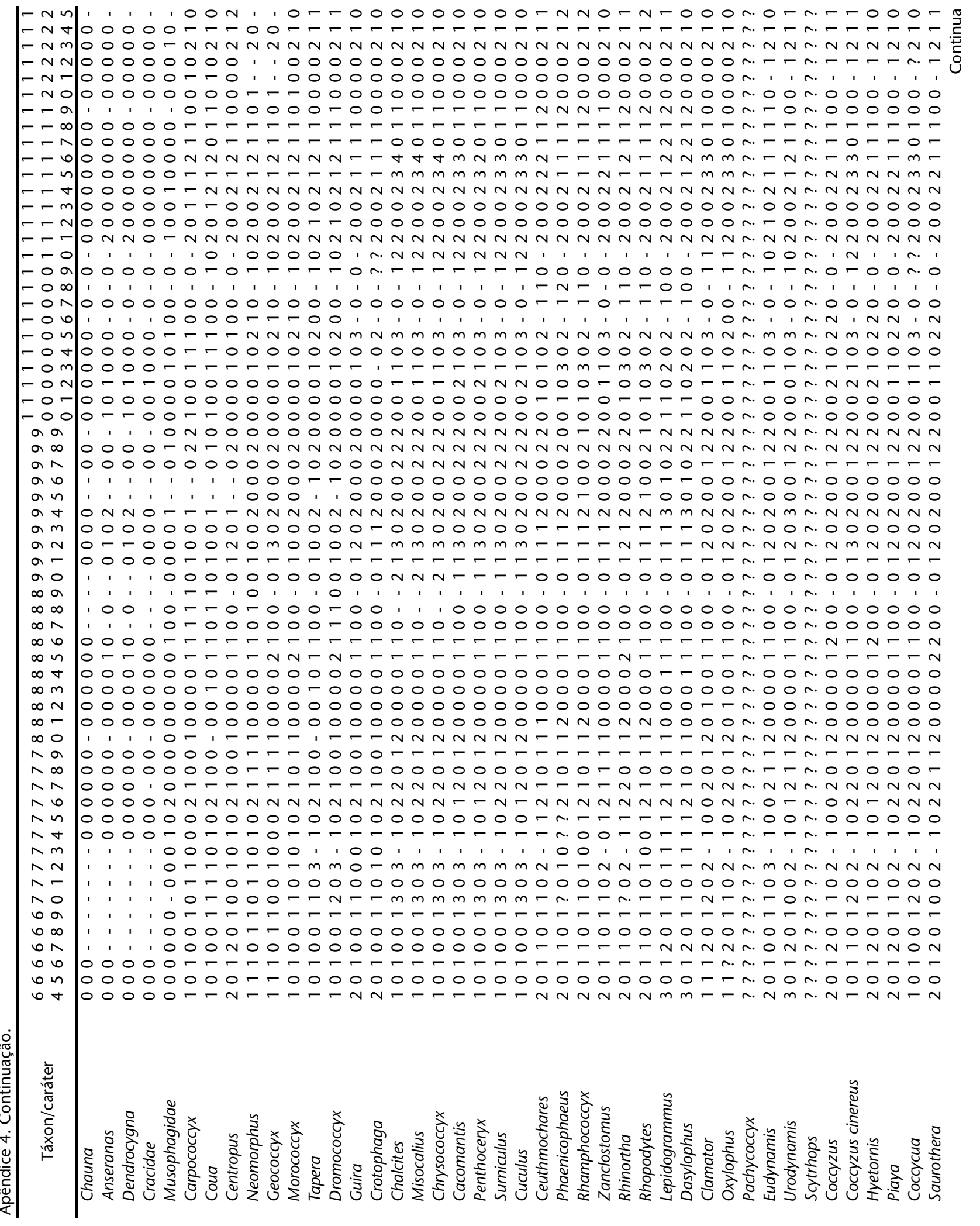




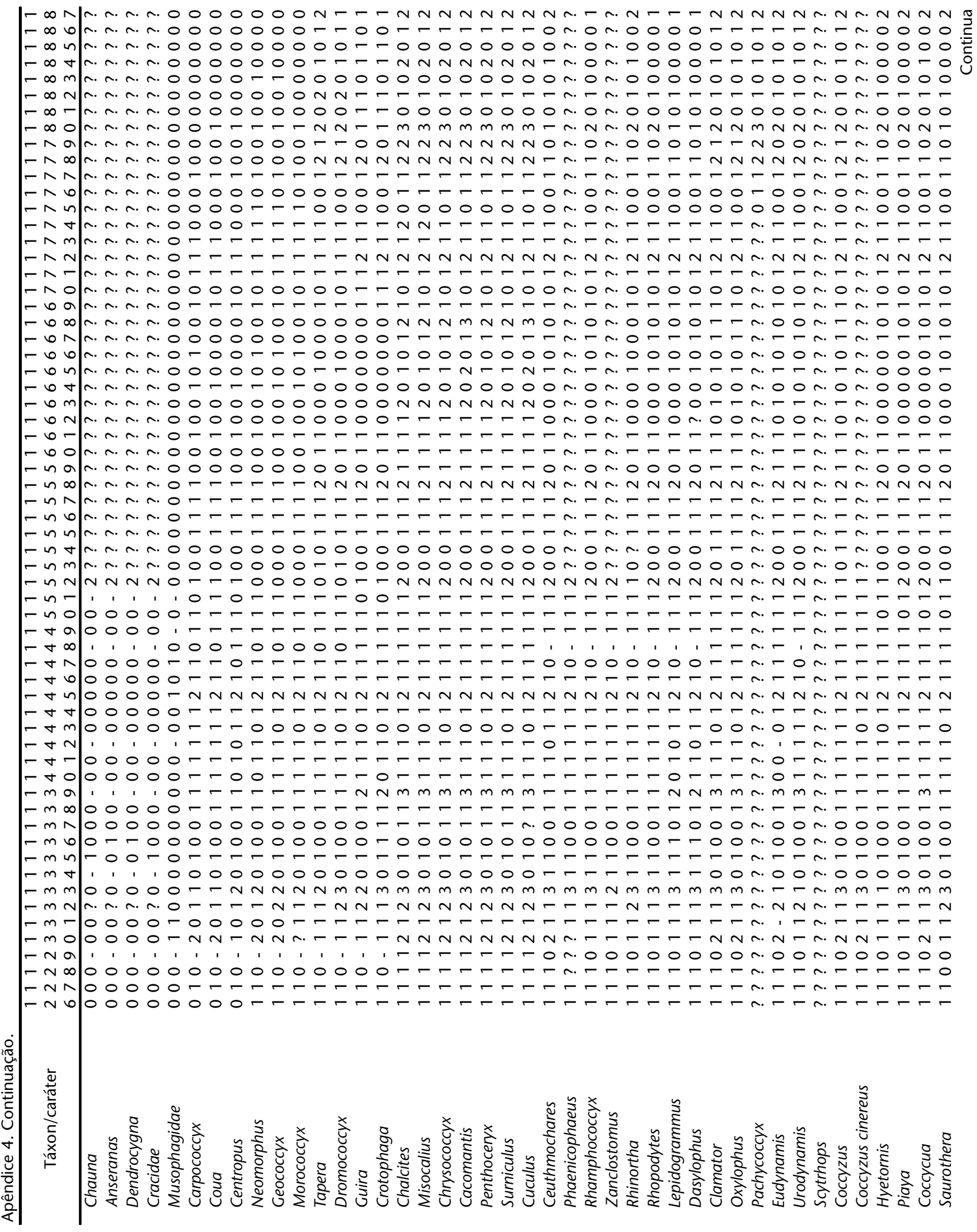

Revista Brasileira de Zoologia 23 (3): 608-629, setembro, 2006 
inin o

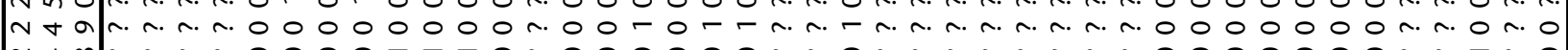

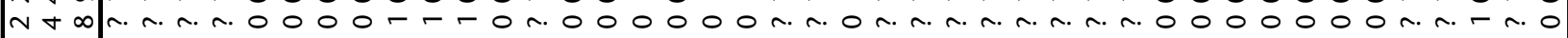

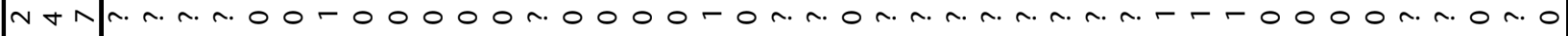

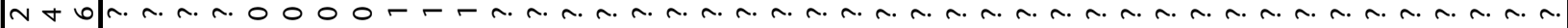

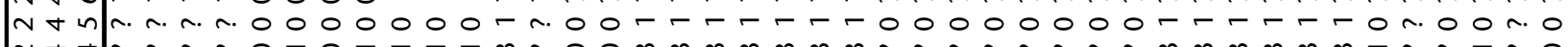

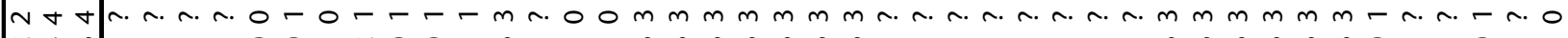

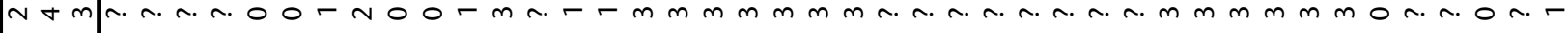

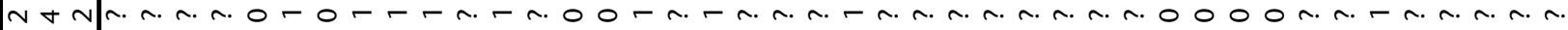

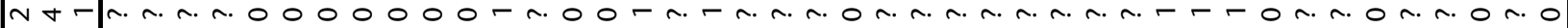

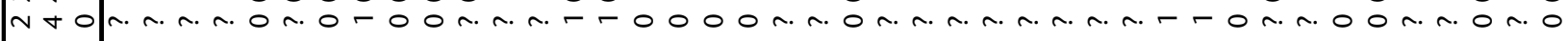

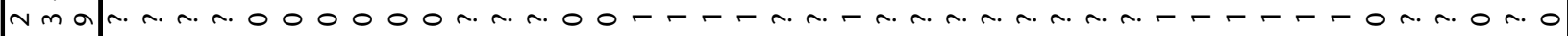

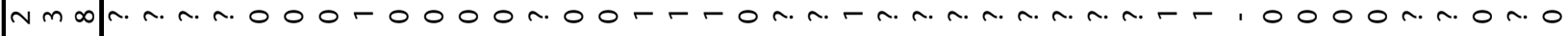
$\sim m \wedge \mid n . r . r . r .000000000 n . r-0000$ r. Nm $\log$. n. n. n. 0 -

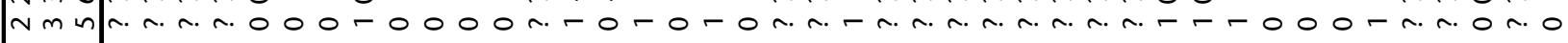

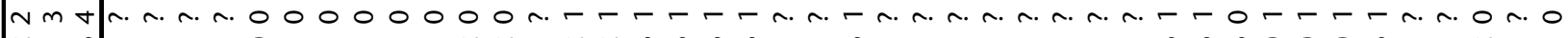

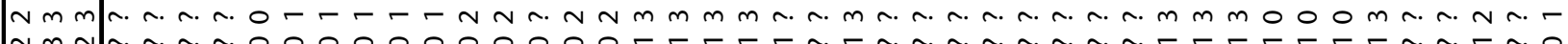

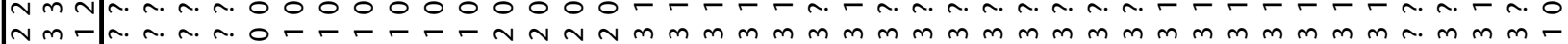

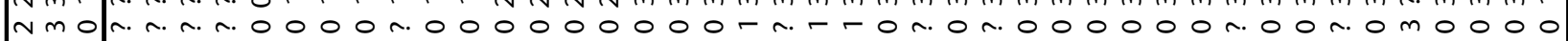

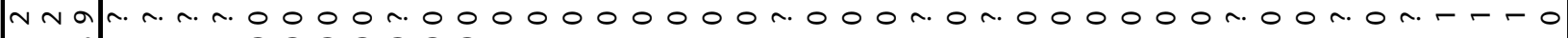
N N

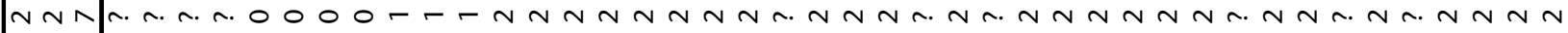
Nก

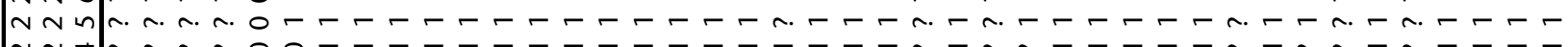

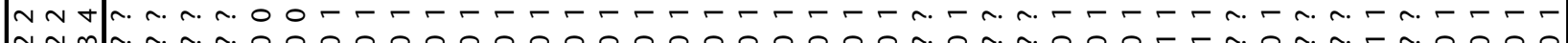

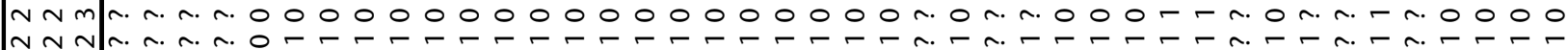

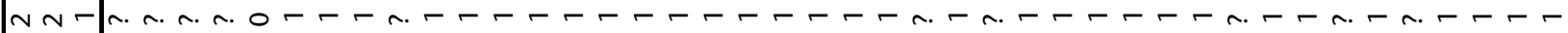

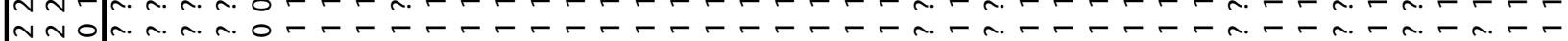
n n a

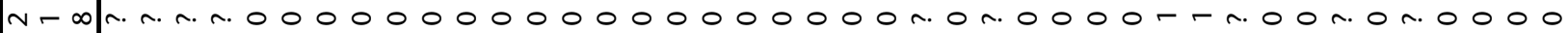

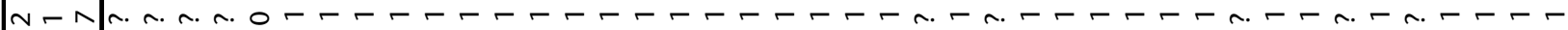

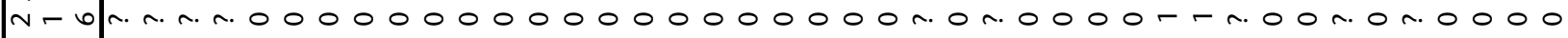

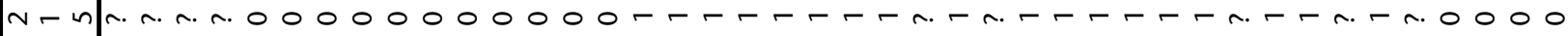

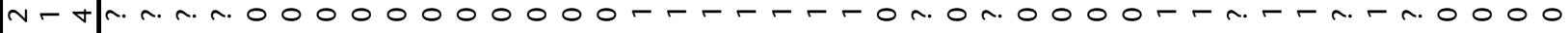

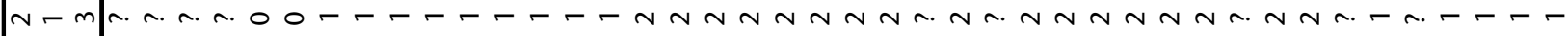

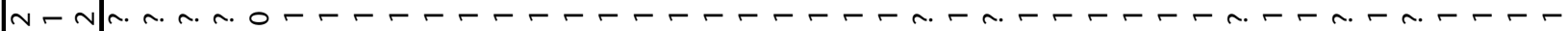

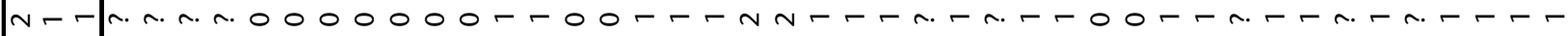

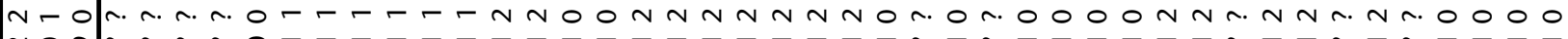

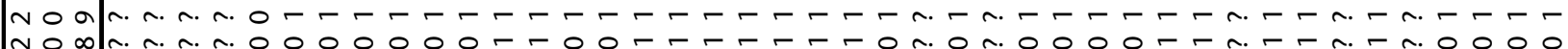

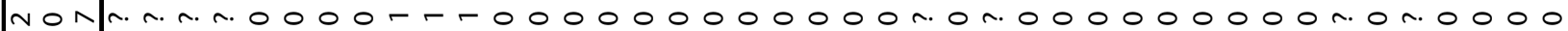
N 0 o

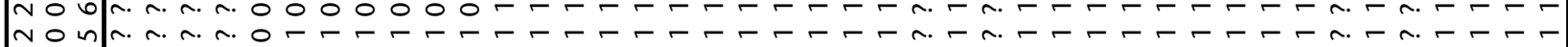

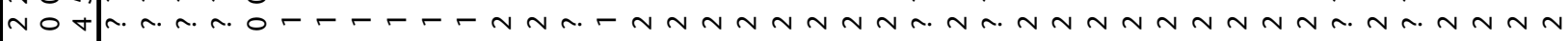

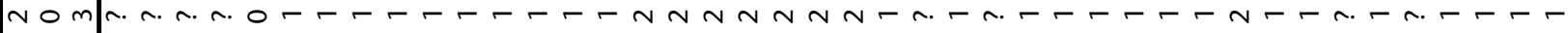

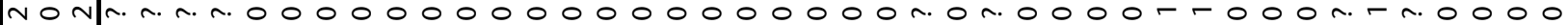

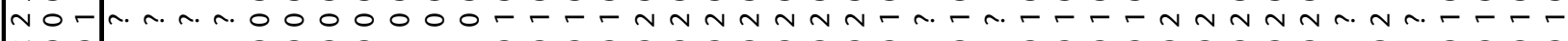

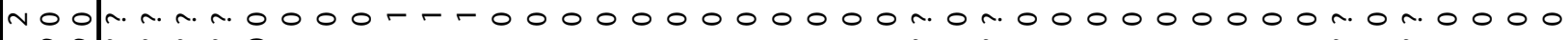

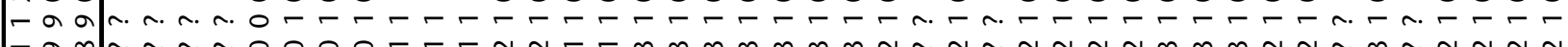

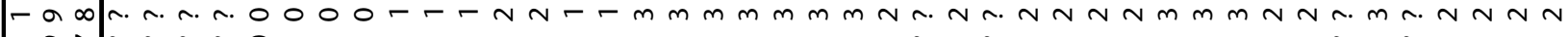
- anjn. n. - 00 r

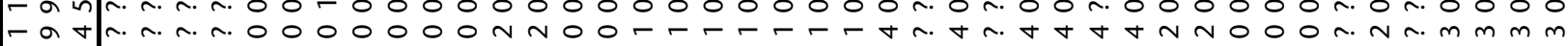

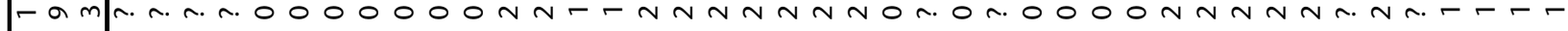
- a nan.r.r.

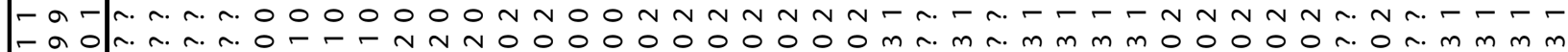

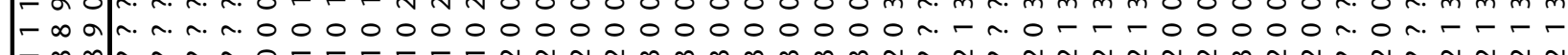

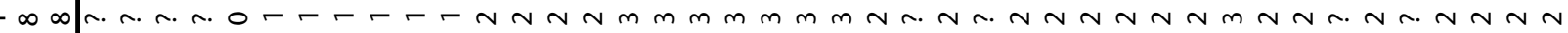


Apêndice 5. Lista de caracteres em cada ramo e respectivos números de passos e polaridade (entre parênteses) da análise cladística com base na osteologia craniana e pós-craniana (Hughes 2000) e comportamento e ecologia (HuGHes 1996).

Ramo $1: 1(1,0 \rightarrow 1) ; 8(1,0 \rightarrow 1) ; 11(1,0 \rightarrow 1) ; 13(2,0 \rightarrow 2) ; 21(1,0 \rightarrow 1) ; 23(1,0 \rightarrow 1) ; 28(1,0 \rightarrow 1) ; 30(1,0 \rightarrow 1) ; 31(1,1 \rightarrow 2)$; $32(1,0 \rightarrow 1) 34(1,0 \rightarrow 1) ; 36(1,0 \rightarrow 1) ; 44(1,1 \rightarrow 2) ; 53(1,0 \rightarrow 1) ; 56(1,0 \rightarrow 1) ; 60(1,0 \rightarrow 1) ; 64(1,0 \rightarrow 1) ; 66(1,0 \rightarrow 1) ; 69(1$, $0 \rightarrow 1) ; 72(1,0 \rightarrow 1) ; 77(1,0 \rightarrow 1) ; 80(1,0 \rightarrow 1) ; 85(1,0 \rightarrow 1) ; 91(1,0 \rightarrow 1) ; 98(1,1 \rightarrow 2) ; 105(1,1 \rightarrow 2) ; 112(1,1 \rightarrow 2) ; 115(1,1$ $\rightarrow 2) ; 116(1,0 \rightarrow 1) ; 117(2,0 \rightarrow 2) ; 118(1,0 \rightarrow 1) ; 119(1,0 \rightarrow 1) ; 124(1,1 \rightarrow 2) ; 125(1,0 \rightarrow 1) ; 128(1,0 \rightarrow 1) ; 131(1,1 \rightarrow 2) ; 133$ $(1,0 \rightarrow 1) ; 134(2,0 \rightarrow 2) ; 136(1,0 \rightarrow 1) ; 139(1,0 \rightarrow 1) ; 140(1,0 \rightarrow 1) ; 141(1,0 \rightarrow 1) ; 142(1,0 \rightarrow 1) ; 145(1,0 \rightarrow 1) ; 146(1,1 \rightarrow 2) ;$ $147(1,0 \rightarrow 1) ; 150(1,0 \rightarrow 1) ; 151(1,0 \rightarrow 1) ; 156(1,0 \rightarrow 1) ; 157(1,0 \rightarrow 1) ; 158(1,0 \rightarrow 1) ; 159(1,0 \rightarrow 1) ; 162(1,0 \rightarrow 1) ; 165(1,0$ $\rightarrow 1) ; 170(1,0 \rightarrow 1) ; 172(1,0 \rightarrow 1) ; 173(1,0 \rightarrow 1) ; 174(1,0 \rightarrow 1) ; 178(1,0 \rightarrow 1) ; 181(1,0 \rightarrow 1) ; 189(1,0 \rightarrow 1) ; 191(1,0 \rightarrow 1) ; 193$ $(1,0 \rightarrow 1) ; 198(1,0 \rightarrow 1) ; 200(1,0 \rightarrow 1) ; 204(1,0 \rightarrow 1) ; 205(1,0 \rightarrow 1) ; 206(1,0 \rightarrow 1) ; 210(1,0 \rightarrow 1) ; 211(1,0 \rightarrow 1) ; 213(1,0 \rightarrow 1) ;$ $214(1,0 \rightarrow 1) ; 218(1,0 \rightarrow 1) ; 220(1,0 \rightarrow 1) ; 221(1,0 \rightarrow 1) ; 222(1,0 \rightarrow 1) ; 223(1,0 \rightarrow 1) ; 225(1,0 \rightarrow 1) ; 226(1,0 \rightarrow 1) ; 227(1,0$ $\rightarrow 1) ; 232(1,0 \rightarrow 1) ; 234(1,0 \rightarrow 1), 237(1,0 \rightarrow 1) ; 243(1,0 \rightarrow 1) ; 244(1,0 \rightarrow 1) ; 245(1,0 \rightarrow 1)$. Ramo $2: 14(1,1 \rightarrow 0) ; 17(1,0 \rightarrow 1)$; $25(2,0 \rightarrow 2) ; 56(1,1 \rightarrow 2) ; 62(1,0 \rightarrow 1) ; 63(1,0 \rightarrow 1) ; 71(1,0 \rightarrow 1) ; 88(1,0 \rightarrow 1) ; 100(1,0 \rightarrow 1) ; 104(1,0 \rightarrow 1) ; 114(1,0 \rightarrow 1) ; 122$ $(1,0 \rightarrow 1) ; 134(1,2 \rightarrow 1)$. Ramo 3: $19(1,0 \rightarrow 1) ; 31(2,2 \rightarrow 4) ; 34(1,1 \rightarrow 2) ; 37(1,0 \rightarrow 1) ; 45(1,0 \rightarrow 1) ; 55(1,0 \rightarrow 1) ; 70(1,0 \rightarrow 1)$; $94(1,1 \rightarrow 2) ; 106(1,1 \rightarrow 2) ; 107(1,0 \rightarrow 1) ; 127(1,0 \rightarrow 1) ; 132(1,0 \rightarrow 1) ; 152(1,0 \rightarrow 1) ; 175(1,0 \rightarrow 1) ; 199(1,0 \rightarrow 1) ; 228(1,0 \rightarrow$ 1); $234(1,1 \rightarrow 2) ; 247(1,0 \rightarrow 1)$. Ramo $4: 20(1,0 \rightarrow 1) ; 26(1,0 \rightarrow 1) ; 41(1,0 \rightarrow 1) ; 47(2,0 \rightarrow 2) ; 51(1,0 \rightarrow 1) ; 56(1,1 \rightarrow 2) ; 59(1$, $0 \rightarrow 1) ; 79(1,0 \rightarrow 1) ; 85(1,1 \rightarrow 2) ; 110(1,0 \rightarrow 1) ; 121(1,0 \rightarrow 1) ; 153(1,1 \rightarrow 0) ; 167(1,0 \rightarrow 1) ; 176(1,0 \rightarrow 1) ; 191(1,1 \rightarrow 2) ; 201$ $(1,0 \rightarrow 1) ; 208(1,0 \rightarrow 1) ; 220(1,1 \rightarrow 0) ; 249(1,0 \rightarrow 1)$. Ramo 5: $28(1,1 \rightarrow 0) ; 65(1,0 \rightarrow 1) ; 68(1,0 \rightarrow 1) ; 70(1,1 \rightarrow 0) ; 78(1,0 \rightarrow$ 1); $125(1,1 \rightarrow 0) ; 132(1,1 \rightarrow 0) ; 184(1,0 \rightarrow 1) ; 234(1,2 \rightarrow 1) ; 244(1,1 \rightarrow 0)$. Ramo $6: 17(1,0 \rightarrow 1) ; 25(1,0 \rightarrow 1) ; 32(1,1 \rightarrow 2) ; 64$ $(1,1 \rightarrow 2) ; 92(1,0 \rightarrow 1) ; 131(1,2 \rightarrow 1) ; 134(1,2 \rightarrow 3) ; 149(1,0 \rightarrow 1) ; 159(1,1 \rightarrow 2) ; 161(1,0 \rightarrow 1) ; 165(1,1 \rightarrow 0) ; 173(1,1 \rightarrow 2) ;$ $179(2,0 \rightarrow 2) ; 183(1,0 \rightarrow 1) ; 185(1,0 \rightarrow 1) ; 188(1,0 \rightarrow 1) ; 189(1,1 \rightarrow 2) ; 191(1,1 \rightarrow 0) ; 193(1,1 \rightarrow 0) ; 194(1,0 \rightarrow 1) ; 202(1,0$ $\rightarrow 1) ; 207(1,0 \rightarrow 1) ; 211(1,1 \rightarrow 0) ; 228(1,1 \rightarrow 2) ; 229(1,0 \rightarrow 1) ; 232(1,1 \rightarrow 2)$. Ramo 7: $8(1,1 \rightarrow 2) ; 54(1,0 \rightarrow 1) ; 55(1,1 \rightarrow 0)$; $72(1,1 \rightarrow 2) ; 166(1,0 \rightarrow 1) ; 181(1,1 \rightarrow 2) ; 188(1,1 \rightarrow 2) ; 192(1,0 \rightarrow 1) ; 195(2,0 \rightarrow 2) ; 199(1,1 \rightarrow 2) ; 205(1,1 \rightarrow 2) ; 212(1,0 \rightarrow$ 1). Ramo 8: $8(1,2 \rightarrow 3) ; 20(1,0 \rightarrow 1) ; 47(1,0 \rightarrow 1) ; 51(1,0 \rightarrow 1) ; 64(1,2 \rightarrow 1) ; 70(1,1 \rightarrow 2) ; 72(1,2 \rightarrow 3) ; 92(1,1 \rightarrow 0) ; 96(1,0 \rightarrow$ 1); $107(1,1 \rightarrow 0) ; 110(1,0 \rightarrow 1) ; 113(1,0 \rightarrow 1) ; 126(1,0 \rightarrow 1) ; 149(1,1 \rightarrow 0) ; 153(1,1 \rightarrow 0) ; 154(1,0 \rightarrow 1) ; 173(1,2 \rightarrow 1) ; 180(1$, $0 \rightarrow 1) ; 183(1,1 \rightarrow 2) ; 187(1,0 \rightarrow 1) ; 192(1,1 \rightarrow 2) ; 194(1,1 \rightarrow 2) ; 209(1,0 \rightarrow 1) ; 211(2,0 \rightarrow 2) ; 220(1,1 \rightarrow 2) ; 242(1,0 \rightarrow 1) ; 244$ $(2,1 \rightarrow 3) ; 245(2,1 \rightarrow 3) ; 246(1,0 \rightarrow 1)$. Ramo 9: $3(1,0 \rightarrow 1) ; 10(1,0 \rightarrow 1) ; 25(1,1 \rightarrow 0) ; 32(1,2 \rightarrow 3) ; 37(1,1 \rightarrow 2) ; 45(1,1 \rightarrow 2)$; $52(1,0 \rightarrow 1) ; 56(1,1 \rightarrow 0) ; 59(1,0 \rightarrow 1) ; 67(1,0 \rightarrow 1) ; 79(1,0 \rightarrow 1) ; 99(2,0 \rightarrow 2) ; 102(1,0 \rightarrow 1) ; 107(1,1 \rightarrow 2) ; 116(1,1 \rightarrow 2) ; 129$ $(1,0 \rightarrow 1) ; 144(1,0 \rightarrow 1) ; 153(1,1 \rightarrow 2) ; 168(1,0 \rightarrow 1) ; 179(1,2 \rightarrow 1) ; 191(3,0 \rightarrow 3) ; 195(1,2 \rightarrow 3) ; 216(1,0 \rightarrow 1) ; 232(1,2 \rightarrow 3) ;$ $233(1,0 \rightarrow 1)$. Ramo 10: $7(1,0 \rightarrow 1) ; 11(1,1 \rightarrow 2) ; 31(1,4 \rightarrow 3) ; 33(1,0 \rightarrow 1) ; 39(2,0 \rightarrow 2) ; 67(1,1 \rightarrow 2) ; 77(1,1 \rightarrow 2) ; 80(1,1 \rightarrow$ 2); $92(1,1 \rightarrow 2) ; 97(1,0 \rightarrow 1) ; 123(1,0 \rightarrow 1) ; 131(1,1 \rightarrow 2)$. Ramo 11: $22(1,0 \rightarrow 1) ; 76(1,2 \rightarrow 1) ; 160(1,0 \rightarrow 1) ; 164(1,0 \rightarrow 1) ; 169$ $(1,0 \rightarrow 1) ; 179(1,1 \rightarrow 2) ; 180(1,0 \rightarrow 1) ; 187(1,0 \rightarrow 1) ; 191(3,3 \rightarrow 0) ; 192(1,1 \rightarrow 2) ; 194(1,1 \rightarrow 2) ; 195(1,3 \rightarrow 2) ; 199(1,2 \rightarrow 3) ;$ $202(1,1 \rightarrow 2) ; 209(1,0 \rightarrow 1) ; 211(2,0 \rightarrow 2) ; 215(1,0 \rightarrow 1) ; 220(1,1 \rightarrow 2) ; 234(1,2 \rightarrow 3) ; 235(1,0 \rightarrow 1) ; 236(1,0 \rightarrow 1)$. Ramo $12:$ $30(1,1 \rightarrow 2) ; 31(1,3 \rightarrow 4) ; 106(1,2 \rightarrow 3) ; 107(2,2 \rightarrow 0) ; 110(1,0 \rightarrow 1) ; 140(2,1 \rightarrow 3) ; 144(1,1 \rightarrow 0) ; 195(1,2 \rightarrow 1) ; 214(1,1 \rightarrow$ 2); $240(1,0 \rightarrow 1) ; 243(1,1 \rightarrow 0) ; 244(2,1 \rightarrow 3) ; 245(2,1 \rightarrow 3) ; 246(1,0 \rightarrow 1)$. Ramo 13: $11(1,2 \rightarrow 3) ; 62(1,0 \rightarrow 1) ; 64(1,2 \rightarrow 1)$; $70(1,1 \rightarrow 2) ; 76(1,1 \rightarrow 2) ; 111(1,0 \rightarrow 1) ; 116(1,2 \rightarrow 3) ; 117(1,2 \rightarrow 3) ; 118(1,1 \rightarrow 0) ; 123(1,1 \rightarrow 0) ; 239(1,0 \rightarrow 1) ; 242(1,0 \rightarrow$ 1); $248(1,0 \rightarrow 1)$. Ramo 14: $7(1,1 \rightarrow 2) ; 34(1,2 \rightarrow 3) ; 58(1,1 \rightarrow 2) ; 61(1,0 \rightarrow 1) ; 67(1,2 \rightarrow 1) ; 92(1,2 \rightarrow 3) ; 102(1,1 \rightarrow 2) ; 111(1$, $1 \rightarrow 2) ; 163(1,0 \rightarrow 1) ; 164(1,1 \rightarrow 2) ; 169(1,1 \rightarrow 2) ; 177(1,0 \rightarrow 1) ; 180(1,1 \rightarrow 2) ; 181(1,2 \rightarrow 3) ; 189(1,2 \rightarrow 3) ; 204(1,1 \rightarrow 2)$. Ramo 15: $8(1,2 \rightarrow 3) ; 14(1,1 \rightarrow 0) ; 16(1,0 \rightarrow 1) ; 33(1,1 \rightarrow 2) ; 67(1,1 \rightarrow 0) ; 70(1,2 \rightarrow 3) ; 72(1,2 \rightarrow 3) ; 90(1,0 \rightarrow 1) ; 97(1,1 \rightarrow 2) ; 120$ $(1,0 \rightarrow 1) ; 130(1,0 \rightarrow 1) ; 133(1,1 \rightarrow 2) ; 138(1,0 \rightarrow 1) ; 185(1,1 \rightarrow 2) ; 243(1,0 \rightarrow 1) ; 248(1,1 \rightarrow 0) ; 250(1,0 \rightarrow 1)$. Ramo 16: $7(1$, $2 \rightarrow 1) ; 12(1,0 \rightarrow 1) ; 40(1,0 \rightarrow 1) ; 55(1,0 \rightarrow 1) ; 90(1,1 \rightarrow 2) ; 102(1,2 \rightarrow 1) ; 117(1,3 \rightarrow 4)$. Ramo $17: 4(1,0 \rightarrow 1) ; 175(1,1 \rightarrow 2) ;$ $197(1,0 \rightarrow 1)$. Ramo 18: $56(1,0 \rightarrow 1) ; 231(1,0 \rightarrow 1) ; 242(1,1 \rightarrow 0)$. Ramo 19: $14(1,0 \rightarrow 1) ; 76(1,2 \rightarrow 1) ; 212(1,1 \rightarrow 2)$. Ramo $20:$ $166(1,1 \rightarrow 2) ; 169(1,2 \rightarrow 3)$. Ramo 21: $7(1,1 \rightarrow 0) ; 35(1,0 \rightarrow 1) ; 57(1,0 \rightarrow 1) ; 65(10 \rightarrow 1) ; 82(1,0 \rightarrow 1) ; 155(1,0 \rightarrow 1) ; 195(1,1$ $\rightarrow 2) ; 203(1,0 \rightarrow 1) ; 217(1,0 \rightarrow 1) ; 219(1,0 \rightarrow 1) ; 224(1,0 \rightarrow 1) ; 237(1,1 \rightarrow 0) ; 241(1,0 \rightarrow 1)$. Ramo $22: 5(1,1 \rightarrow 0) ; 16(1,0 \rightarrow 1) ;$ $18(1,0 \rightarrow 1) ; 22(1,1 \rightarrow 0) ; 27(1,0 \rightarrow 1) ; 30(1,2 \rightarrow 3) ; 78(1,0 \rightarrow 1) ; 116(1,2 \rightarrow 1) ; 133(1,1 \rightarrow 2) ; 134(2,3 \rightarrow 1) ; 169(1,1 \rightarrow 0) ; 180$ $(1,1 \rightarrow 0) ; 195(1,1 \rightarrow 0) ; 199(1,3 \rightarrow 2) ; 234(3,3 \rightarrow 0) ; 236(1,1 \rightarrow 0)$. Ramo 23: $5(1,1 \rightarrow 0) ; 46(1,0 \rightarrow 1) ; 151(1,1 \rightarrow 0) ; 166(1$, $1 \rightarrow 0) ; 190(1,0 \rightarrow 1) ; 216(1,1 \rightarrow 0) ; 230(1,0 \rightarrow 1)$. Ramo 24: $106(1,2 \rightarrow 1) ; 117(1,2 \rightarrow 1) ; 131(1,2 \rightarrow 1) ; 185(1,1 \rightarrow 0)$. Ramo $25:$ $39(1,2 \rightarrow 3) ; 46(1,1 \rightarrow 0) ; 86(1,1 \rightarrow 2) ; 144(1,1 \rightarrow 0) ; 153(1,2 \rightarrow 1) ; 233(1,1 \rightarrow 0) ; 234(1,2 \rightarrow 1) ; 245(1,1 \rightarrow 0)$. Ramo $26: 38$ $(1,0 \rightarrow 1) ; 75(1,0 \rightarrow 1) ; 93(1,0 \rightarrow 1) ; 120(1,0 \rightarrow 1) ; 135(1,0 \rightarrow 1) ; 148(1,1 \rightarrow 0) ; 194(1,1 \rightarrow 0) ; 195(1,3 \rightarrow 4) ; 214(1,1 \rightarrow 2)$. Ramo 27: $81(1,0 \rightarrow 1), 101(1,0 \rightarrow 1), 102(1,1 \rightarrow 0) ; 108(1,0 \rightarrow 1) ; 120(1,1 \rightarrow 2) ; 126(1,0 \rightarrow 1)$. Ramo $28: 3(1,1 \rightarrow 0) ; 8(1,2 \rightarrow 1) ; 31$ $(1,4 \rightarrow 3) ; 52(1,1 \rightarrow 0) ; 81(1,1 \rightarrow 2) ; 103(2,1 \rightarrow 3) ; 116(1,2 \rightarrow 1)$. Ramo 29: $72(1,2 \rightarrow 1) ; 185(1,1 \rightarrow 0) ; 188(1,2 \rightarrow 1) ; 190(1$, $0 \rightarrow 1)$. Ramo 30: $31(1,3 \rightarrow 4) ; 48(1,0 \rightarrow 1) ; 74(1,1 \rightarrow 0) ; 99(1,2 \rightarrow 1) ; 117(1,2 \rightarrow 1) ; 126(1,1 \rightarrow 2)$. Ramo $31: 6(1,0 \rightarrow 1) ; 29(1$, $0 \rightarrow 1) ; 52(1,0 \rightarrow 1) ; 95(1,0 \rightarrow 1)$. Ramo 32: $43(1,0 \rightarrow 1) ; 55(1,0 \rightarrow 1) ; 56(1,0 \rightarrow 1) ; 64(1,2 \rightarrow 3) ; 67(1,1 \rightarrow 2) ; 73(1,0 \rightarrow 1) ; 81$

Revista Brasileira de Zoologia 23 (3): 608-629, setembro, 2006 
$(2,2 \rightarrow 0) ; 84(1,0 \rightarrow 1) ; 94(1,2 \rightarrow 3) ; 96(1,0 \rightarrow 1) ; 100(1,0 \rightarrow 1) ; 103(1,3 \rightarrow 2) ; 109(1,1 \rightarrow 0) ; 118(1,1 \rightarrow 2) ; 137(1,0 \rightarrow 1) ; 140$ $(1,1 \rightarrow 2) ; 143(1,1 \rightarrow 0) ; 181(1,2 \rightarrow 1) ; 212(1,1 \rightarrow 0)$. Ramo 33: $2(1,0 \rightarrow 1) ; 6(1,0 \rightarrow 1) ; 9(1,0 \rightarrow 1) ; 16(1,0 \rightarrow 1) ; 19(1,1 \rightarrow 0)$; $25(1,1 \rightarrow 2) ; 31(2,4 \rightarrow 2) ; 34(1,2 \rightarrow 1) ; 35(1,0 \rightarrow 1), 42(1,0 \rightarrow 1) ; 49(1,0 \rightarrow 1) ; 50(1,0 \rightarrow 1) ; 117(1,2 \rightarrow 1) ; 140(1,1 \rightarrow 2) ; 152$ $(1,1 \rightarrow 0) ; 171(1,0 \rightarrow 1) ; 182(1,0 \rightarrow 1) ; 186(1,0 \rightarrow 1) ; 235(1,0 \rightarrow 1) ; 238(1,0 \rightarrow 1) ; 241(1,0 \rightarrow 1) ; 243(1,1 \rightarrow 0) ; 245(1,1 \rightarrow 0)$. 